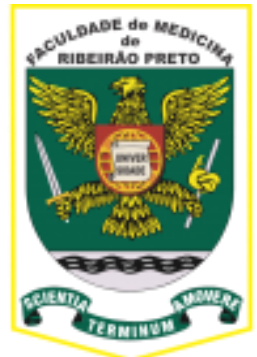

UNIVERSIDADE DE SÃO PAULO

FACULDADE DE MEDICINA DE RIBEIRÃO PRETO

PROGRAMA DE PÓS-GRADUAÇÃO EM FARMACOLOGIA

\title{
ATIVAÇÃO DO COMPLEXO NLRP3 INFLAMASSOMA COMO POTENCIAL MECANISMO ENVOLVIDO NA DISFUNÇÃO VASCULAR EM RESPOSTA A NÍVEIS SUPRAFISIOLÓGICOS DE TESTOSTERONA
}

JULIANO VILELA ALVES

RIBEIRÃO PRETO-SP 
JULIANO VILELA ALVES

\section{ATIVAÇÃO DO COMPLEXO NLRP3 INFLAMASSOMA COMO POTENCIAL MECANISMO ENVOLVIDO NA DISFUNÇÃO VASCULAR EM RESPOSTA A NÍVEIS SUPRAFISIOLÓGICOS DE TESTOSTERONA}

Dissertação de Mestrado apresentada à Faculdade de Medicina de Ribeirão Preto da Universidade de São Paulo para obtenção do título de Mestre em Ciências.

Área de concentração: Farmacologia

Orientadora: Prof ${ }^{\mathrm{a}}$. Dr ${ }^{\mathrm{a}}$. Rita de Cássia Aleixo Tostes Passaglia

RIBEIRÃO PRETO-SP

2018 
Autorizo a reprodução e divulgação total ou parcial deste trabalho, por qualquer meio convencional ou eletrônico, para fins de estudo e pesquisa, desde que citada a fonte.

Departamento Técnico do Sistema Integrado de Bibliotecas da USP

Universidade de São Paulo

Ficha Catalográfica

Alves, Juliano Vilela.

Ativação do complexo NLPR3 inflamassoma como potencial mecanismo envolvido na disfunção vascular em resposta a níveis suprafisiológicos de testosterona. Ribeirão Preto, 2018. 90 p., $30 \mathrm{~cm}$.

Dissertação de Mestrado, apresentada à Faculdade de Medicina de Ribeirão Preto/Universidade de São Paulo - Área de concentração: Farmacologia.

Orientadora: Tostes, Rita de Cássia

1. Testosterona. 2. Espécies reativas de oxigênio. 3. Inflamassoma NLRP3. 4. Disfunção vascular. 


\section{FOLHA DE APROVAÇÃO}

Autor: Juliano Vilela Alves

Título: Ativação do complexo NLRP3 inflamassoma como potencial mecanismo envolvido na disfunção vascular em resposta a níveis suprafisiológicos de testosterona.

Dissertação de Mestrado apresentada à Faculdade de Medicina de Ribeirão Preto da Universidade de São Paulo para obtenção do título de Mestre em Ciências.

Área de concentração: Farmacologia

Orientadora: Prof ${ }^{\mathrm{a}}$. Dr ${ }^{\mathrm{a}}$. Rita de Cássia Aleixo Tostes Passaglia

Aprovado em: I I

\section{Banca Examinadora}

Presidente: $\quad$ Assinatura:

Nome:

Instituição:

Examinador(a): $\quad$ Assinatura:

Nome:

Instituição:

Examinador(a): $\quad$ Assinatura:

Nome:

Instituição:

Examinador(a): $\quad$ Assinatura:

Nome:

Instituição: 
À Deus pelo dom da vida, pois na Tua palavra encontro a força que preciso para continuar caminhando

À minha mãe Leiá Gilka e ao meu irmão Alexandre Vilela:

Pelo conforto e segurança de uma família sem igual. Obrigado por tudo! 


\section{Agradecimentos}

Nunca saberemos o quão forte somos até que ser forte seja a única escolha!

À Deus acima de todas as coisas!

À Prof ${ }^{a}$. Dr ${ }^{a}$. Rita de Cássia Aleixo Tostes Passaglia, pela oportunidade, orientação, incentivo e pela confiança em mim depositada.

Ao Rafael Menezes. Obrigado pela co-orientação, amor e companheirismo, você sempre será uma pessoa especial em minha vida! Obrigada por ser esse exemplo de profissional, um homem amoroso, generoso e humilde, que inspira a todos.

À Prof ${ }^{a}$. Dr ${ }^{a}$. Núbia Lobato. Obrigado pelo suporte científico, o qual foi fundamental para o desenvolvimento desse trabalho.

Ao Prof. Dr. Fernando Carneiro. Obrigado pela ajuda científica e ensinamentos no dia-a-dia.

À todos os membros da minha família, em especial à minha mãe Leiá que nunca mediu esforços para a realização de todos os meus sonhos. É sempre bom ter uma família unida, que faz questão de vibrar todas as vitórias e conquistas juntos. Ter uma família que você pode confiar, contar nas horas boas e ruins.

À banca examinadora pelas críticas e sugestões que contribuíram para o enriquecimento deste trabalho.

Aos amigos. É um privilégio quando temos ao nosso lado pessoas tão maravilhosas como vocês. Nunca terei como agradecer pelo apoio que vocês me ofereceram em momentos em que eu tanto precisei. Agradeço imensamente pelo companheirismo e pela amizade que me fizeram crescer e superar cada desafio.

Aos amigos de Ribeirão Preto: Wanessa, Jonathas, Jéssica e Paulo que tornaram os dias mais agradáveis e pelo convívio. 
Aos amigos de laboratório: Camila André, Nathanne, Aline, Josiane, Sara, Camila Zanotto, Diane, Thiago Dias, Rafael Fais, Júlio, Allan, Pedro, Daniel, Juliana, Fernanda, Débora, Carla Pavan, Fabíola e Giuliana pela colaboração, pelos ensinamentos e pelo convívio agradável.

Aos funcionários do Departamento de Farmacologia da FMRP-USP, em especial à Soninha, Fátima Helena, Ramon, Gislaine, Eleni e Tadeu pelo carinho e atenção.

À Prof ${ }^{\mathrm{a}}$. Dr ${ }^{\mathrm{a}}$. Hiromi Yanagisawa, Prof. Dr. Yoshito Yamashiro e alunos do laboratório pelo acolhimento e auxílio nos experimentos.

À Universidade de São Paulo, à Faculdade de Medicina de Ribeirão Preto por me concederem toda estrutura para realização desse trabalho e também ao Centro de Pesquisas em Doenças Inflamatórias (CRID), às agências de fomento CAPES, CNPq e FAPESP pelo apoio financeiro para realização desse trabalho.

À todos que direta ou indiretamente contribuíram para este trabalho, o meu muito obrigado!! 
"O saber a gente aprende com os metres e os livros. A sabedoria se aprende é com a vida e com os humildes."

Cora Coralina 


\section{Resumo}




\section{ALVES, JV. Ativação do complexo NLRP3 inflamassoma como potencial mecanismo}

envolvido na disfunção vascular em resposta a níveis suprafisiológicos de testosterona. 2018. 90 p. Dissertação (Mestrado em Farmacologia) - Faculdade de Medicina de Ribeirão Preto, Universidade de São Paulo, Ribeirão Preto, 2018.

O aumento da concentração sérica de testosterona está associado tanto a fatores de risco cardiovascular, incluindo obesidade abdominal e hipertensão arterial, como diretamente a doenças cardiovasculares (DCVs). Há evidências que a testosterona pode modular, positivamente, componentes envolvidos em processos de oxirredução (redox) e inflamatório, incluindo a geração de espécies reativas de oxigênio (EROs) e produção de citocinas próinflamatórias e anti-inflamatórias. O inflamassoma NLRP3 é um componente do sistema imunológico inato e regulador importante da inflamação crônica. Sua ativação pode ser mediada pelo aumento de EROs, contribuindo para o processo inflamatório presente em diversas DCVs. Considerando que a testosterona representa uma fonte importante na produção de EROs, foi testada a hipótese que níveis suprafisiológicos de testosterona induzem ativação do complexo NLRP3 inflamassoma, com consequente prejuízo da função vascular. Esse estudo avaliou se níveis suprafisiológicos de testosterona são capazes de ativar o inflamassoma NLRP3 e se esta ativação contribui para alterações na reatividade vascular. Nosso estudo demonstrou que níveis supra fisiológicos de testosterona alteraram a função vascular, com participação dos receptores para andrógenos em camundongos C57BL/6J wild type (WT). Estes efeitos da testosterona não foram observados em camundongos WT incubados com MCC950 (inibidor do receptor NLRP3) e knockout NLRP3 (NLRP3\%). Além disso, a testosterona aumentou a geração vascular de EROs, determinada pela fluorescência de lucigenina e dihidroetidina. A geração de EROs foi prevenida por cianeto de carbonil mclorofenil hidrazona (CCCP), um desacoplador mitocondrial. A testosterona em níveis suprafisiológicos aumentou a expressão vascular de caspase-1 e interleucina-1 $\beta$ (IL-1 $\beta$ ), como determinado por Western Blotting e Elisa, respectivamente. Esses dados sugerem que níveis suprafisiológicos de testosterona induzem disfunção vascular via geração de EROs e ativação do inflamassoma NLRP3.

Palavras chave: Testosterona, espécies reativas de oxigênio, inflamassoma NLRP3 e disfunção vascular. 
Abstract

arastract 


\section{ALVES, JV. Activation of the complex NLRP3 inflammasome as a potential mechanism}

involved in vascular dysfunction in response to supraphysiological levels of testosterone. 2018. 90 p. Dissertation (Master of Sciences in Pharmacology) -Ribeirao Preto Medical School, University of Sao Paulo, Ribeirao Preto, 2018.

Increased serum testosterone concentration is associated with both cardiovascular risk factors, including abdominal obesity and hypertension, and cardiovascular disease (CVD). There is evidence that testosterone positively modulates components involved in oxidative and inflammatory processes, including the generation of reactive oxygen species (ROS) and production of pro-inflammatory and anti-inflammatory cytokines. NLRP3 inflammasome is a component of the innate immune system and an important modulator of chronic inflammation. NLRP3 activation can be mediated by increased levels of ROS, contributing to chronic inflammation in several CVDs. Considering that testosterone induces ROS production, we tested tested the hypothesis that supraphysiological levels of testosterone activates the NLRP3 inflammasome, with consequent impairment of vascular function. This study evaluated whether supraphysiological levels of testosterone activate NLRP3 inflammasome and whether NLRP3 activation contributes to testosterone-induced vascular dysfunction. Our study demonstrated that supraphysiological levels of testosterone, via activation of androgen receptors, altered vascular function in C57BL/6J wild type (WT) mice. The vascular effects of testosterone were not observed in WT mice incubation with MCC950 (NLRP3 receptor inhibitor) and NLRP3 (NLRP3 \%) knockout mice. In addition, testosterone increased vascular generation of ROS, as determined by lucigenin and dihydroetidine the fluorescence. ROS generation was prevented by carbonyl m-chlorophenyl hydrazone cyanide (CCCP), a mitochondrial uncoupler. Testosterone at supraphysiological levels increased the vascular expression of caspase-1 and interleukin-1 $\beta$ (IL-1 $)$ ), as determined by Western blotting and Elisa, respectively. These data suggest that supraphysiological levels of testosterone induce vascular dysfunction through ROS generation and activation of the NLRP3 inflammasome.

Keywords: Testosterone, reactive oxygen species, NLRP3 inflammasome and vascular dysfunction. 
Lista de abreviaturas, siglas e símbolos 


\begin{tabular}{|c|c|}
\hline$\mu g$ & micrograma \\
\hline$\mu \mathrm{L}$ & microlitro \\
\hline$\mu \mathrm{m}$ & micrômetro \\
\hline $\mathrm{ACh}$ & acetilcolina \\
\hline ANGII & angiotensina II \\
\hline BSA & albumina bovino sérica \\
\hline $\mathrm{C}$ & célsius \\
\hline $\mathrm{Ca}^{2+}$ & cálcio \\
\hline $\mathrm{CaCl}_{2}$ & cloreto de cálcio \\
\hline CARD & domínio de recrutamento de caspase \\
\hline СCCP & carbonil cianida 3-clorofenil-hidrazona \\
\hline CMLV & célula muscular lisa vascular \\
\hline $\mathrm{CO}_{2}$ & dióxido de carbono \\
\hline CONCEA & Conselho Nacional de Experimentação Animal \\
\hline $\mathrm{COX}_{2}$ & ciclooxigenase tipo 2 \\
\hline DAMPs & padrões moleculares associados a danos celulares \\
\hline DCVs & doenças cardiovasculares \\
\hline DHE & dihidroetidina \\
\hline DHT & dihidrotestosterona \\
\hline DNA & ácido desoxirribonucleico \\
\hline $\mathrm{E}$ & etídio \\
\hline $\mathrm{EC}_{50}$ & $\begin{array}{l}\text { concentração efetiva do agonista que produz } 50 \% \text { do efeito } \\
\text { máximo }\end{array}$ \\
\hline EDTA & ácido etileno diamino tetra-acético \\
\hline EGTA & ácido tetra acético etileno glicol \\
\hline EHO & 2-hidróxi etídio \\
\hline EPM & erro padrão da média \\
\hline EROs & espécies reativas de oxigênio \\
\hline ET-1 & endotelina-1 \\
\hline $\mathrm{FE}$ & fenilefrina \\
\hline
\end{tabular}


Flu

h

IL-10

IL-12

IL-18

IL-1 $\beta$

IL-6

iNOS

$\mathrm{K}^{+}$

$\mathrm{KCl}$

$\mathrm{kg}$

$\mathrm{KH}_{2} \mathrm{PO}_{4}$

LPS

LRR

M

MCC950

MCP-1

mg

$\mathrm{MgSO}_{4}$

$\min$

$\mathrm{ml}$

$\mathrm{mm}$

$\mathrm{mM}$

$\mathrm{mN}$

$\mathrm{NaCl}$

NADPH

$\mathrm{NaHCO}_{3}$

NATCH

$\mathrm{NF}-\kappa \mathrm{B}$

NLRP3\% flutamida, antagonista de receptor para andrógeno

horas

interleucina-10

interleucina-12

interleucina-18

interleucina- 1 beta

interleucina-6

óxido nítrico sintase induzível

potássio

cloreto de potássio

quilogramas

fosfato monopotássico

lipopolissacarídeo

repetições ricas em leucina

molar

inibidor do receptor do NLRP3

proteína quimiotática para monócitos 1

miligramas

sulfato de magnésio

minuto

mililitro

milímetro

milimolar

milinewton

cloreto de sódio

fosfato de dinucleótido de nicotinamida e adenina

bicarbonato de sódio

domínio de ligações e oligmerização de nucleotídeos

fator de transcrição nuclear kappa B

knockouts NLRP3 
NLRs

$\mathrm{O}_{2}^{-}$

$\mathrm{O}_{2}$

PAMPs

PBS

$\mathrm{pD}_{2}$

$\mathrm{PGE}_{2}$

PRRs

PT

PYD

rpm

SDS

SFB

TLR

$\mathrm{TNF} \alpha$

V

VCAM-1

WT receptores do tipo NOD

ânion superóxido

oxigênio

padrões moleculares associados a patógenos

tampão fosfato salino

logaritmo negativo da concentração efetiva do agonista que produz $50 \%$ do efeito máximo

prostaglandina $\mathrm{E}_{2}$

receptores de reconhecimento padrão

propionato de testosterona

domínio de pirina

rotação por minuto

dodecil sulfato de sódio

soro fetal bovino

receptores do tipo Toll

fator de necrose tumoral alfa

volt

molécula de adesão celular vascular-1

camundongo tipo selvagem 
Lista de figuras 
Figura 1 - Esquema representativo da hipótese

Figura 2 - A incubação de aorta torácicas de camundongos C57BL/6J wild type com testosterona promove disfunção vascular

Figura 3 - $\mathrm{O}$ tratamento de camundongos C57BL/6J wild type com propionato de testosterona promove disfunção vascular

Figura 4 - A testosterona induz disfunção vascular via ativação de receptores para andrógeno

Figura 5 - Efeitos dos níveis suprafisiológicos de testosterona na geração vascular de espécies reativas de oxigênio mitocondriais 56

Figura 6 - A testosterona induz disfunção vascular via geração de espécies reativas de oxigênio mitocondriais 58

Figura 7 - A testosterona induz disfunção vascular via inflamassoma NLRP3 60

Figura 8 - A testosterona induz disfunção vascular via inflamassoma NLRP3

Figura 9 - O propionato de testosterona induz disfunção vascular via inflamassoma NLRP3

Figura 10 - A incubação de aortas torácicas com testosterona e tratamento de camundongos C57BL/6J wild type com propionato de testosterona induzem aumento de componentes que indicam ativação do inflamassoma NLRP3 
Lista de tabelas 
Tabela 1 - Anticorpos utilizados nos ensaios de Western blotting

Tabela 2 - Valores de $p \mathrm{D}_{2}$ para fenilefrina e acetilcolina em aortas torácicas provenientes de camundongos C57BL/6J wild type incubadas com testosterona e/ou veículo 49

Tabela 3 - Valores de $p \mathrm{D}_{2}$ para fenilefrina e acetilcolina em aortas torácicas provenientes de camundongos C57BL/6J wild type tratados com propionato de testosterona e/ou veículo

Tabela 4 - Valores de $p \mathrm{D}_{2}$ para fenilefrina e acetilcolina, em presença de veículo e/ou flutamida, em aortas torácicas provenientes de camundongos C57BL/6J wild type incubadas com testosterona 54

Tabela 5 - Valores de $p \mathrm{D}_{2}$ para fenilefrina e acetilcolina, em presença de veículo e/ou $\mathrm{CCCP}$, em aortas torácicas provenientes de camundongos $\mathrm{C} 57 \mathrm{BL} / 6 \mathrm{~J}$ wild type incubadas com testosterona 58

Tabela 6 - Valores de $p \mathrm{D}_{2}$ para fenilefrina e acetilcolina, em presença de veículo e/ou MCC950, em aortas torácicas provenientes de camundongos C57BL/6J wild type incubadas com testosterona 60

Tabela 7 - Valores de $p \mathrm{D}_{2}$ para fenilefrina e acetilcolina em aortas torácicas provenientes de camundongos C57BL/6J wild type e knockouts para NLRP3 incubadas com testosterona e/ou veículo 61

Tabela 8 - Valores de $p \mathrm{D}_{2}$ para fenilefrina e acetilcolina em aortas torácicas provenientes de camundongos C57BL/6J wild type e knockouts para NLRP3 tratados com propionato de testosterona e/ou veículo 
Sumário 
1.1 Testosterona endógena e o sistema cardiovascular ...................................................... 25

1.2 Função da testosterona na inflamação vascular .......................................................... 27

1.3 Função do inflamassoma NLRP3 em doenças cardiovasculares ................................. 30

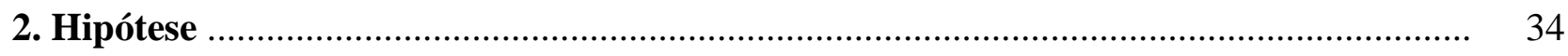

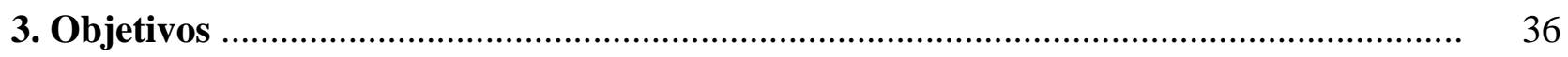

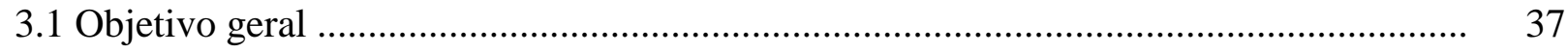

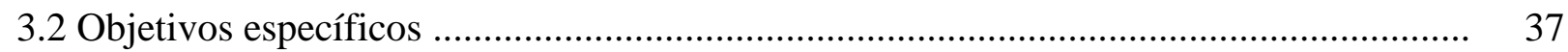

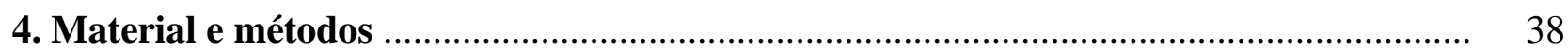

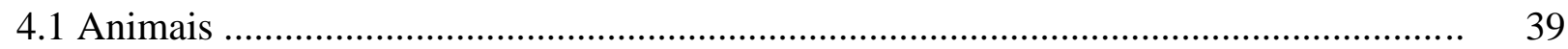

4.2 Tratamento com propionato de testosterona …...................................................... 39

4.3 Medida da testosterona plasmática …......................................................................... 39

4.4 Estudo de reatividade em anéis de aorta isolados ....................................................... 40

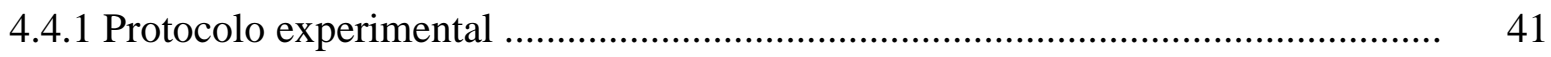

4.5 Análise da expressão proteica por Western blotting .............................................. 42

4.6 Quantificação de citocinas por Elisa ..................................................................... 43

4.7 Estudo da geração de espécies reativas de oxigênio ................................................ 44

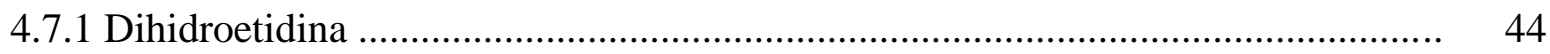

4.7.2 Medida da produção de ânion superóxido por Lucigenina .................................. 44

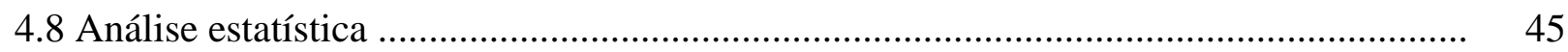

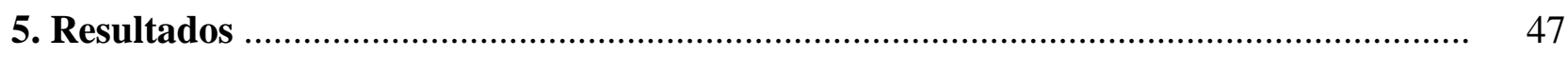

5.1 Efeitos da incubação com testosterona sobre as respostas contrátil à fenilefrina e dilatadora à acetilcolina em aortas torácicas de camundongos ................................................... 48

5.2 Efeitos do tratamento de camundongos com propionato de testosterona nas respostas de aortas torácicas a fenilefrina e acetilcolina ........................................................... 50

5.3 Contribuição dos receptores para andrógenos na disfunção vascular induzida pela incubação com testosterona 
5.4 Geração vascular de espécies reativas de oxigênio mitocondriais induzidas por níveis suprafisiológicos de testosterona

5.5 Contribuição das espécies reativas de oxigênio mitocondriais para a disfunção vascular induzida pela incubação com testosterona

5.6 Contribuição do inflamassoma NLRP3 para a disfunção vascular induzida pela incubação com testosterona

5.7 Contribuição do inflamassoma NLRP3 para disfunção vascular induzida pelo tratamento de camundongos com propionato de testosterona

5.8 Avaliação dos componentes do inflamassoma NLRP3 em modelo experimental com níveis suprafisiológicas de testosterona 


\section{Introdução}




\subsection{Testosterona endógena e o sistema cardiovascular}

As doenças cardiovasculares (DCVs) estão classificadas como as doenças mais prevalentes e mais estudadas em diversos países desenvolvidos. Os mecanismos envolvidos na etiologia ou complicações associadas às mesmas ainda não foram completamente elucidados. As DCVs estão associadas a uma parcela significativa de incapacidade e a aproximadamente um terço de todas as mortes no mundo (WHO, 2017). Essas alterações tornam-se tipicamente evidentes em indivíduos fisicamente inativos ou obesos, com dislipidemia, diabetes ou hipertensão arterial. Uma vez que esses fatores de risco relacionados ao estilo de vida têm se tornado comuns na maioria dos países em desenvolvimento, a incapacidade e as mortes por DCVs têm, também, aumentado significativamente nesses países (Novak, 1998; Gersh et al., 2010; Gaziano et al., 2012).

Independentemente das variações regionais na prevalência de DCVs, o impacto das mesmas é maior em homens do que aquele observado em mulheres (Groban et al., 2016). Essa discrepância entre os sexos não é explicada por simples diferenças nos perfis dos fatores de risco cardiovasculares, o que sugere a contribuição de outros fatores, como os hormônios sexuais.

A testosterona é o andrógeno masculino predominante e mais ativo. Além de regular as funções reprodutivas e sexuais, a testosterona modula o tônus vascular e o desempenho cardíaco. A testosterona é produzida pelos testículos sob estímulo dos hormônios gonadotróficos presentes na hipófise anterior que, por sua vez, são controlados pelos hormônios liberadores de gonadotrofinas produzidos em neurônios do hipotálamo. Um homem jovem adulto produz diariamente cerca de 3 a $10 \mathrm{mg}$ de testosterona livre, o que se traduz em valores séricos de 300 a 1000 ng / dL (Sá et al., 2009; Lopes et al., 2012).

A suplementação com esteroides anabolizantes androgênicos é utilizada clinicamente para prevenir e aliviar muitos sintomas associados ao hipogonadismo e envelhecimento (Kalra 
et al., 2010), embora não haja ainda implicações claras a respeito do impacto desse procedimento sobre o sistema cardiovascular. Em pacientes com baixos níveis plasmáticos de testosterona total (<300 ng / dL), a suplementação com testosterona é utilizada para melhorar o desempenho muscular, a densidade mineral óssea, as funções cognitiva e sexual, bem como para prevenir o desenvolvimento de complicações como síndrome metabólica e doenças cardiovasculares (Bassil et al., 2009). As recomendações para suplementação com testosterona determinam doses de 75 a $100 \mathrm{mg}$ / por semana no tratamento do hipogonadismo masculino (Bhasin et al., 2010). Curiosamente, uma pesquisa envolvendo a utilização de drogas de abuso entre fisioculturistas e levantadores de peso apontou que as doses de anabolizantes androgênicos esteroides utilizadas nestes casos são de 5 a 29 vezes maiores que as doses utilizadas na suplementação para aumento de massa muscular e redução de gordura corporal (Perry et al., 2005; Nordstrom et al., 2012). Esse uso ilícito de doses suprafisiológicas de testosterona levantou questões sobre os possíveis efeitos adversos associados a níveis elevados do hormônio.

Estudos realizados em homens que utilizam doses suprafisiológicas de testosterona para aumentar o desenvolvimento e desempenho muscular demonstraram, claramente, aumento do risco de desenvolvimento de hipertensão arterial, hipertrofia ventricular esquerda, infarto agudo do miocárdio e morte cardíaca súbita (Hartgens \& Kuipers, 2004). Além disso, cardiomiócitos estimulados com testosterona exibem aumento nos níveis de cálcio $\left(\mathrm{Ca}^{2+}\right)$ intracelular, com participação de receptores de membrana para andrógenos. O aumento dos níveis de $\mathrm{Ca}^{2+}$ intracelular depende da liberação de $\mathrm{Ca}^{2+}$ presente em vesículas intracelulares por mecanismos dependentes de fosfolipase C e inositol trifosfato (Estrada et al., 2003; Vicencio et al., 2006). $\mathrm{O} \mathrm{Ca}^{2+}$ exerce papel importante na geração de espécies reativas de oxigênio (EROs) mitocondriais (Zhang et al., 2014; Viola \& Hool, 2014). Por sua vez, o desbalanço na produção de EROs tem participação especial no desenvolvimento de DCVs, 
por aumento na produção de oxidantes, detrimento de defesas antioxidantes e diminuição de óxido nítrico na vasculatura e rins (Touyz, 2003; Sedeek, Hebert et al., 2009).

Os achados acima reforçam a sugestão de que o aumento nos níveis de testosterona está associado a muitos fatores de risco individuais para DCVs. Apesar da relevância clínica, a grande ressalva em nossa compreensão básica dos eventos moleculares subjacentes à disfunção vascular associada a níveis elevados de testosterona representa um gargalo para a concepção eficaz de abordagens intervencionistas nestas condições.

\subsection{Função da testosterona na inflamação vascular}

A inflamação está envolvida na gênese de complicações cardiovasculares em várias condições clínicas. A reação inflamatória compreende uma sequência de eventos coordenada pelo sistema imune e envolve interações complexas entre células inflamatórias, tais como neutrófilos, linfócitos, monócitos/macrófagos, e células vasculares. Essas interações resultam em aumento da produção tecidual de mediadores solúveis, tais como proteínas do sistema complemento, quimiocinas, citocinas, EROs, aminas vasoativas e eicosanoides, acompanhado pelo aumento da expressão de moléculas de adesão celular em leucócitos circulantes e células endoteliais (Fullerton \& Gilroy, 2016).

De relevância no processo inflamatório, destacam-se as citocinas e polipeptídeos produzidos por células dos componentes inato e adaptativo do sistema imunológico. As citocinas são importantes na modulação da inflamação, desencadeando e regulando, por exemplo, o recrutamento de neutrófilos e monócitos para o local da lesão (Liddiard et al., 2011), o aumento na permeabilidade vascular e a geração de EROs durante a resposta inflamatória (Espinosa, 2012).

Há evidências importantes de que a testosterona modula a expressão e liberação de citocinas. Notavelmente, concentrações fisiológicas de testosterona foram associadas a 
aumento da porcentagem de monócitos produtores de interleucina-12 (IL-12) e interleucina$1 \beta$ (IL-1 $\beta$ ) in vivo (Posma, 2004). O tratamento crônico in vivo com testosterona aumentou a expressão de ciclooxigenase $2(\mathrm{COX}-2)$ e da isoforma induzível da sintase de óxido nítrico (iNOS) em vasos cerebrais de ratos submetidos a estímulo com endotoxina, após acidente vascular cerebral isquêmico. A incubação direta de vasos da pia mater com lipopolissacarídeo (LPS) também resultou em níveis aumentados de COX-2 e de prostaglandina $\mathrm{E}_{2}\left(\mathrm{PGE}_{2}\right)$ (Razmara, 2005), sustentando a sugestão que a testosterona possui efeitos pró-inflamatórios importantes e diretos em vasos cerebrais, os quais contribuiriam para a inflamação cerebrovascular (Hawk, 1998).

De maneira semelhante, nosso grupo demonstrou que a testosterona, por meio de efeitos genômicos e não genômicos, induz a geração de EROs em cultura de células de músculo liso vascular (CMLV), por mecanismos dependentes da enzima oxidante NADPH oxidase, efeito não abolido na presença de inibidor da enzima P450 aromatase, que converte testosterona em estrógeno (Chignalia et al., 2012). Esse efeito também foi evidenciado in vivo na microcirculação, onde a testosterona induziu a migração de leucócitos, por vias dependentes de COX-2 e NADPH oxidase, além de aumentar a produção de EROs, componente central na progressão de eventos inflamatórios (Chignalia et al., 2015). O envolvimento da mitocôndria na geração de EROs induzida por testosterona também foi demonstrado pelo nosso grupo. A geração de EROs mitocondrial, por sua vez, medeia o efeito pró-apoptótico da testosterona em CMLV (Lopes et al., 2014).

Além da modulação na produção de citocinas induzida pela testosterona, Death e colaboradores sugeriram a ausência de interação direta entre a ativação de receptores

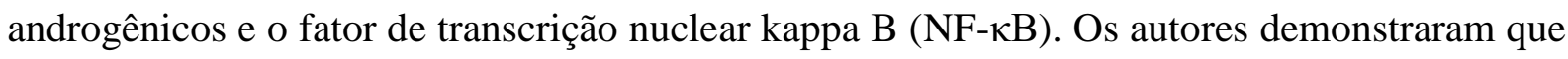
o tratamento com dihidrotestosterona (DHT), um metabólito ativo da testosterona, diminuiu o

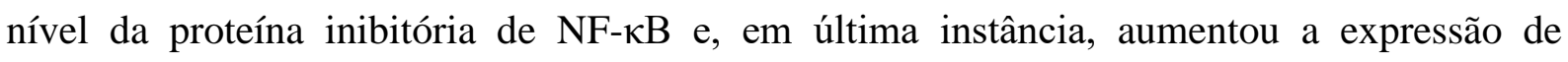


molécula de adesão celular vascular-1 (VCAM-1) em células endoteliais. Além disso, o grupo demonstrou que a DHT tem pouco efeito sobre a expressão de VCAM-1 em células endoteliais provenientes de doadoras do sexo feminino, em contraste com o aumento significativo observado nas células endoteliais provenientes de indivíduos do sexo masculino (Death et al., 2004), o que sugere que a menor expressão de receptores de androgênio em mulheres, em relação a indivíduos do sexo masculino, contribui para a especificidade relacionada ao sexo dos efeitos pró-aterogênicos promovidos pela DHT.

Vários outros estudos também demonstraram que há aumento na expressão de moléculas de adesão estimulada por citocinas em células endoteliais tratadas com andrógenos (McCrohon et al., 1999; Mukherjee et al., 2002; Death et al., 2004).

Em contraste com os estudos acima mencionados, uma série de estudos experimentais sugere papel modulador benéfico dos andrógenos nas respostas inflamatórias (Dalal et al., 1997; Kimura et al., 1998; Ben-Nathan et al., 1999). Independentemente dos protocolos experimentais desses estudos, na maioria dos casos, a resposta à testosterona parece ser semelhante, com andrógenos atenuando a produção de citocinas inflamatórias, tais como fator de necrose tumoral alfa (TNF $\alpha)$, IL-1 $\beta$ e interleucina-6 (IL-6), em células humanas, em macrófagos (D'Agostino, 1999), monócitos (Li, 1993), fibroblastos gengivais (Gornstein, 1999), osteoblastos (Bellido, 1995; Hofbauer, 1999) e células endoteliais (Hatakeyama, 2002). Além disso, testosterona estimula a produção de citocinas antiinflamatórias, como interleucina-10 (IL-10) (Bebo, 1999, Liva, 2001). A conversão da testosterona em estradiol pela ação da enzima aromatase, expressa em células endoteliais, também foi descrita como sendo um mecanismo importante envolvido, pelo menos em parte, no efeito atenuador da aterogênese pela testosterona (Chan et al., 2015). Nesse sentido, demonstrou-se que a conversão de testosterona em estradiol é seguida pela ativação do 
receptor de estrogênio e pela subsequente redução da expressão gênica e proteica de VCAM1, um dos primeiros passos no processo de aterogênese.

O processo de envelhecimento, que se sobrepõe a uma diminuição progressiva, lenta e contínua da testosterona e outros androgênios, é conhecidamente acompanhado por um estado pró-inflamatório, caracterizado por níveis crescentes de várias citocinas. Essa relação é reforçada pelos achados de que a terapia de privação de androgênios está associada a níveis aumentados de citocinas pró-inflamatórias e diminuição dos níveis de citocinas antiinflamatórias (Maggio et al., 2005, Maggio et al., 2006). Nesse sentido, estudo de Malkin demonstrou que a terapia de reposição com testosterona em homens com deficiência de androgênios reduziu citocinas pró-inflamatórias, como TNF $\alpha$ e IL-1 $\beta$, juntamente com aumento de IL-10 (Malkin, 2004).

As observações conflitantes sobre os efeitos da testosterona em processos associados à inflamação podem, em parte, ser decorrentes das flutuações dos níveis séricos deste hormônio, uma vez que níveis fisiológicos são capazes de manter a homeostase enquanto níveis sub- ou suprafisiológicos estão associados ao dano cardiovascular. Além disso, parece que diferentes níveis de conversão de testosterona em seus metabólitos, estradiol ou DHT, podem resultar em diferentes efeitos celulares. $\mathrm{O}$ aspecto essencial para desvendar o papel da testosterona na inflamação pode estar relacionado à compreensão da sinalização celular promovida por esse andrógeno, bem como a interação entre receptores e eventos intracelulares que resultam em ações pró- e /ou anti-inflamatórias.

\subsection{Função do inflamassoma NLRP3 nas doenças cardiovasculares}

A ativação do inflamassoma é uma função chave mediada pelo sistema imune inato. Avanços recentes têm contribuído sobremaneira para o entendimento dos mecanismos envolvidos na ativação de inflamassomas. Os receptores de reconhecimento padrão (pattern- 
recognition receptors - PRRs), incluindo receptores do tipo Toll (Toll-like receptors - TLR) encontrados na membrana celular, receptores do tipo domínio de ligação e oligomerização de nucleotídeos (nucleotide binding and oligomerization domain - NOD) (NOD-like receptors NLRs) presentes no citoplasma, entre outros, são componentes importantes na ativação do complexo inflamassoma. Os NLRs são especializados no reconhecimento de padrões moleculares associados a patógenos (pathogen-associated molecular patterns - PAMPs) e danos celulares (danger-associated molecular patterns - DAMPs) (Patel et al., 2017). A ativação desses receptores gera respostas pelo sistema imune de suma importância para a defesa do hospedeiro e reparo tecidual.

Em humanos, os NLRs compreendem uma família com 22 membros que podem ser caracterizados pelos seus domínios: domínio de ligação e oligomerização de nucleotídeos $(\mathrm{NATCH})$, situado entre repetições ricas em leucinas (leucine-rich repeat - LRR); domínio $\mathrm{N}$-terminal efetor, responsável pelo recrutamento de caspase (caspase recruitment domain CARD) e domínio de pirina (pyrin domain - PYD). Os membros NLRs, NODs (NOD1-2, NOD3/NLRC3, NOD4/NLRC5, NOD5/NLRX1，CIITA), NLRPs (NLRP1-14, também conhecidos como NALPs) e a subfamília IPAF (também conhecido como NLRC4) e NAIP, compartilham estruturalmente um único domínio comum, o NATCH (Franchi et al. 2009). Frente a estímulos específicos, esses são capazes de originar complexos multiprotéicos chamados inflamassomas.

O inflamassoma atua como uma plataforma no controle de infecções, por ativar proteases de cisteína, conhecidas como caspases, as quais estão envolvidas em processos inflamatórios ou de apoptose celular. A caspase-1 ativa cliva pró-IL-1 $\beta$ e pró-IL-18, promovendo a maturação destas citocinas, consideradas pró-inflamatórias (Davis, 2011).

Como mencionado, a ativação do complexo NLRP3 inflamassoma pode ser mediada por DAMPs e PAMPs. Para que a ativação funcional do NLRP3 aconteça, dois sinais são 
necessários. O primeiro sinal é mediado pela ativação da via TLR/NF- $\kappa B$, sendo esta ativada por mediadores diversos, como $\mathrm{TNF} \alpha$ e a própria IL-1 $\beta$, culminando no aumento da transcrição gênica de pró-IL-1ß e pró-IL-18 (Bauernfeind et al., 2009).

O segundo sinal envolve a oligomerização do NLRP3, o que leva, de fato, à sua ativação e posterior clivagem e liberação das citocinas maduras. Três mecanismos distintos então envolvidos na oligomerização do NLRP3. O primeiro envolve a ativação de canais iônicos sensíveis a ATP, como os receptores purinérgicos P2X7, responsáveis pelo efluxo de potássio $\left(\mathrm{K}^{+}\right)$(Kahlenberg, 2004). O segundo envolve a geração de EROs mitocondriais (Cassel et al., 2004). A inibição de vários ativadores do NLRP3 que produzem EROs, tais como ATP, nigericina, ácido úrico, sílica, entre outros, suprime a ativação do inflamassoma NLRP3. O terceiro mecanismo envolve partículas, como cristais de urato ou amianto, que causam desestabilização da membrana lisossômica. Danos na membrana lisossomal podem levar ao extravasamento de catepsinas, que são proteases encontradas no citoplasma celular, capazes de oligomerizar o NLRP3 (Ogura, 2006; Jin \& Flavell, 2010). Postulamos que a testosterona pode ser um importante ativador do inflamassoma, visto que o seu excesso pode alterar diversas funções das células, aumentando a produção de EROs e, consequentemente, a liberação de DAMPs.

A ativação do NLRP3 desencadeia processo inflamatório que está envolvido em diversas DCVs, como hipertensão arterial (Shirasunam et al., 2015), aterosclerose (Koka et al., 2017), doença renal crônica (Guo et al., 2017) e insuficiência cardíaca (Fujisue et al., 2017). Sua ativação no sistema cardiovascular ocorre pelo reconhecimento de DAMPs ou PAMPs por células do sistema imune, células endoteliais, CMLV e cardiomiócitos, induzindo produção de citocinas, quimiocinas, miocinas e hormônios dilatadores (Foldes et al., 2010), facilitando não apenas a migração de leucócitos para o local da lesão, mas atuando de modo autócrino e parácrino nestas células (Tousoulis et al., 2010). Nosso grupo demonstrou que a 
ativação do inflamassoma NLRP3 contribui significativamente para disfunção vascular e aumento da pressão arterial média induzidos por aldosterona (Bruder-Nascimento et al., 2016).

O envolvimento do complexo NLRP3 inflamassoma na disfunção vascular e processo inflamatório em resposta a altos níveis de testosterona ainda não foi investigado. Considerando que diversos estudos demonstraram uma forte associação entre o aumento de testosterona e inflamação em vários tipos de células, como linfócitos, plaquetas e células endoteliais, além da estimulação de mediadores como a IL-1 $\beta$, é plausível que concentrações suprafisiológicas de testosterona exerçam efeitos pleiotrópicos, como a inflamação estéril, contribuindo para o dano vascular associado a altos níveis de andrógenos. 
2. Hipótese 
Considerando que 1) altos níveis de testosterona promovem aumento da geração de EROs mitocondrial e estresse oxidativo; 2) níveis elevados de EROs mitocondrial são potentes ativadores do complexo inflamassoma NLRP3, o presente estudo testou a hipótese que aumento nos níveis plasmáticos de testosterona ativa o complexo inflamassoma NLRP3 via aumento de EROs mitocondriais, o que contribui para a disfunção vascular induzida por este andrógeno.

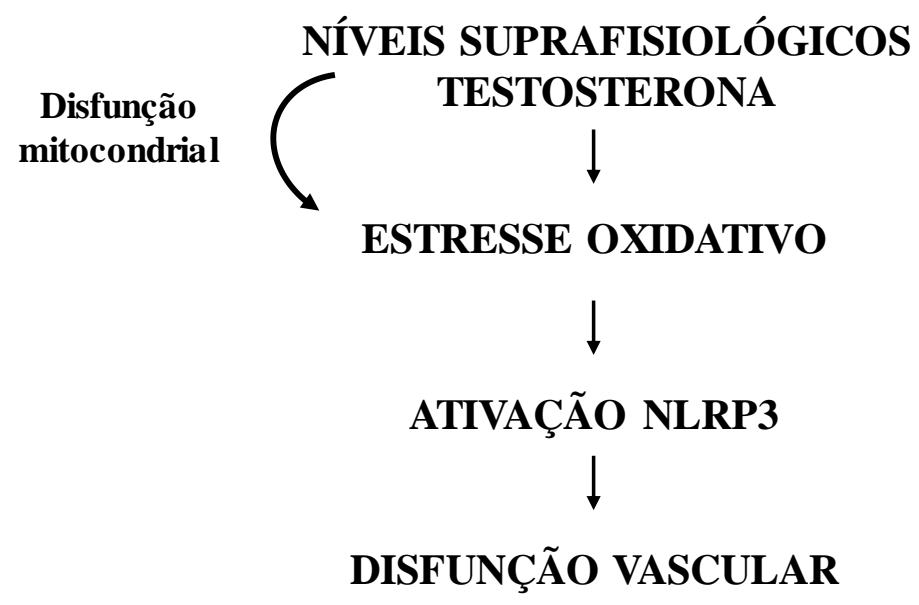

Figura 1 - Esquema representativo da hipótese. 
3. Objetivo 


\subsection{Objetivo geral}

Avaliar a contribuição do complexo NLRP3 inflamassoma nos processos inflamatórios associados à disfunção vascular decorrentes de níveis suprafisiológicos de testosterona, bem como os possíveis mecanismos envolvidos.

\subsection{Objetivos específicos}

1) Confirmar que camundongos tratados com propionato de testosterona apresentam disfunção vascular.

2) Confirmar que níveis suprafisiológicos de testosterona aumentam a produção de EROs mitocondriais na vasculatura.

3) Avaliar se a geração de EROs mitocondriais ativa o complexo NLRP3 inflamassoma na vasculatura de camundongos com níveis suprafisiológicos de testosterona.

4) Determinar as vias de sinalização intracelulares associadas ao estresse oxidativo induzido por altos níveis de testosterona e como elas contribuem para a ativação do NLRP3 inflamassoma e, consequentemente, para as alterações de reatividade vascular em camundongos com níveis suprafisiológicos de testosterona. 
4. Material e métodos 


\subsection{Animais}

Todos os procedimentos experimentais foram aprovados pela Comissão de Ética no Uso de Animais da Faculdade de Medicina de Ribeirão Preto da Universidade de São Paulo (Protocolo $n^{\circ}$ 032/2018), que segue os princípios éticos em experimentação animal adotado pelo Conselho Nacional de Controle de Experimentação Animal (CONCEA).

Foram utilizados camundongos, machos, C57BL/6J (tipo selvagens, Wild Type - WT) adquiridos do Biotério Central da Universidade de São Paulo - Campus de Ribeirão Preto e camundongos knockouts NLRP3 (NLRP3\%) da linhagem C57BL/6J provenientes do Biotério do Departamento de Imunologia, ambos com 6 semanas de idade. Os camundongos foram mantidos durante todo o período experimental em caixas de polipropileno [comprimento (30) x largura (20) x altura (13) $\mathrm{cm}$ e 5 animais por caixa], acondicionadas em ambiente com temperatura controlada de $22 \pm 2{ }^{\circ} \mathrm{C}$, umidade de $50 \pm 5 \%$ e ciclos claro-escuro de 12 horas (h), com livre acesso a água e alimento (Nuvilab CR-1 Irradiada).

\subsection{Tratamento com propionato de testosterona}

Camundongos WT e NLRP3\% com 12 semanas de idade foram tratados com propionato de testosterona (P. Testosterona) $10 \mathrm{mg} / \mathrm{kg}$ por 30 dias, por via subcutânea. Os animais foram divididos em grupos experimentais: 1) WT_Veículo; 2) WT_P. Testosterona; 3) NLRP3\%_Veículo; 4) NLRP3\%_P. Testosterona.

\subsection{Medida de testosterona total plasmática}

Os níveis plasmáticos de testosterona foram determinados utilizando o IMMULITE 1000 Immunoassay System (Enzo Life Sciences). A amostra e o reagente contendo a enzima fosfatase alcalina conjugada com testosterona foram distribuídos em placas de 96 poços, servindo como um recipiente para incubação, lavagem e desenvolvimento do sinal. Após 60 
minutos (min) de incubação, as placas foram lavadas para eliminar qualquer restante de fração não ligada. A fração ligada foi então quantificada utilizando o substrato quimioluminescente dioxetano.

\subsection{Estudo da reatividade vascular em anéis de aorta isolados}

Após anestesia com isoflurano, as aortas torácicas foram removidas e colocadas em placa de Petri contendo solução nutriente de Krebs-Henseleit modificada, a $4{ }^{\circ} \mathrm{C}$, com a seguinte composição (em mM): $\mathrm{NaCl}, 130 ; \mathrm{KCl}, 4,7 ; \mathrm{KH}_{2} \mathrm{PO}_{4}, 1,1 ; \mathrm{MgSO}_{4}, 1,1 ; \mathrm{NaHCO}_{3}$, 15; EDTA, 0,03; $\mathrm{CaCl}_{2}$, 1,6; Glucose, 5,5 (Lobato et al., 2012). A porção mediana da aorta torácica foi dividida em 4 anéis de $2 \mathrm{~mm}$ de comprimento. Os anéis com endotélio foram montados em miógrafo (modelo 620M; Danish Myo Technology - DMT, Copenhagen, Denmark) para estudo da geração de força isométrica. Os anéis foram colocados entre ganchos, um fixo e outro conectado a um transdutor de sinal acoplado a um computador. As preparações permaneceram sob tensão de 5 milinewtons $(\mathrm{mN})$, por 30 min para estabilização, nas cubas do miógrafo contendo solução de Krebs-Henseleit modificada, gaseificada com $95 \%$ de oxigênio $\left(\mathrm{O}_{2}\right)$ e $5 \%$ de dióxido de carbono $\left(\mathrm{CO}_{2}\right)$ e aquecida à $37^{\circ} \mathrm{C}$, com trocas de solução nutriente e ajuste de tensão a cada 10 min.

Após o período de estabilização, as artérias foram estimuladas com cloreto de potássio ( $\mathrm{KCl} 120 \mathrm{mM}$ ), com a finalidade de se avaliar a integridade funcional. Após novo período de lavagem e estabilização por mais $30 \mathrm{~min}$, a integridade do endotélio foi testada avaliando-se o relaxamento à acetilcolina [( $\mathrm{ACh})$ vasodilatador dependente de endotélio, concentração $\left.10^{-6} \mathrm{M}\right]$ em vasos pré-contraídos com fenilefrina [(FE) agonista alfa adrenérgico, na concentração $\left.10^{-6} \mathrm{M}\right]$. A ausência de relaxamento à $\mathrm{ACh}$ foi critério de exclusão dos vasos para os experimentos. Dessa maneira, todos os protocolos experimentais foram realizados em vasos com endotélio. 


\subsubsection{Protocolo experimental}

Para avaliar os efeitos in vitro da incubação com testosterona $\left(10^{-6} \mathrm{M}\right.$ por $\left.2 \mathrm{~h}\right)$ na ativação do inflamassoma NLRP3, geração de EROs mitocondriais e ativação de receptores para andrógenos foram utilizados, respectivamente, inibidor do receptor NLRP3 [MCC950, $10^{-6} \mathrm{M}$ por $30 \mathrm{~min}$ ], desacoplador da fosforilação oxidativa mitocondrial [carbonil cianida 3clorofenil-hidrazona (CCCP), $10^{-6} \mathrm{M}$ por $30 \mathrm{~min}$ ] e antagonista de receptor para andrógeno [Flutamida (Flu), 10 $0^{-5} \mathrm{M}$ por $30 \mathrm{~min}$ ]. Foram realizadas curvas concentração-efeito de caráter cumulativo para PE $\left(10^{-10}-10^{-4} \mathrm{M}\right)$ e ACh $\left(10^{-10}-10^{-4} \mathrm{M}\right)$ em segmentos aórticos com endotélio intacto. Além disso, para verificar os efeitos in vivo dos níveis suprafisiológicos de testosterona na função vascular, utilizamos segmentos aórticos com endotélio intacto provenientes de camundongos tratados com propionato de testosterona (10 mg/kg por 30 dias) para realização de curvas concentração-resposta cumulativas para PE e ACh. As resposta a FE foram expressa como valores de contração em $\mathrm{mN}$ e as respostas a $\mathrm{ACh}$, como porcentagem de relaxamento em relação aos valores de pré-contração induzidos por FE.

\subsection{Análise de expressão proteica por Western blotting}

A expressão proteica de caspase-1, componente do inflamassoma NLRP3 foi determinada pela técnica de western blotting. Aorta torácica de camundongos dos grupos WT_Veículo e WT_ Testosterona (in vitro), WT_Veículo e WT_P. Testosterona (in vivo) foram isoladas, o tecido adiposo perivascular foi removido e as mesmas foram congeladas em nitrogênio líquido. Em seguida, foram pulverizadas e homogeneizadas em tampão de lise gelado. Os extratos teciduais em tampão de lise foram centrifugados a $13000 \mathrm{rpm}$, a $4{ }^{\circ} \mathrm{C}$, por 15 min para a remoção do material insolúvel. Após a centrifugação, o conteúdo proteico total foi quantificado, utilizando o método de Bradford (Bradford, 1976). Em seguida, as amostras foram tratadas com tampão de Laemmli contendo ditiotreitol $200 \mathrm{mM}$ e $50 \mu \mathrm{g}$ de proteína 
total foram submetidas à eletroforese em gel de poliacrilamida (12\%) com dodecil sulfato de sódio em aparelho para mini gel (BioRad, Hercules, USA). Em cada gel havia um marcador com pesos moleculares de valores estabelecidos.

A transferência das proteínas separadas no gel para a membrana de nitrocelulose foi feita eletricamente, por meio de aparelho da BioRad, por 1 h, a 100 V. O tampão foi acrescido de SDS 0,1\% para melhorar a eluição de proteínas de alto peso molecular. A membrana de nitrocelulose foi incubada com uma solução bloqueadora TBS-T [Tris $10 \mathrm{mM}, \mathrm{NaCl} 150 \mathrm{mM}$ e Tween 20 0,02\%] contendo 5\% de albumina bovina sérica (BSA) a $25{ }^{\circ} \mathrm{C}$ durante $1 \mathrm{~h}$ para reduzir a ligação inespecífica de proteínas na membrana. As membranas foram incubadas com anticorpo específico para avaliar a proteína da plataforma inflamassoma NLRP3.

A incubação com anticorpo primário foi feita com solução bloqueadora TBS-T contendo $1 \%$ de BSA overnight na geladeira $\left(4{ }^{\circ} \mathrm{C}\right)$ e a concentração de cada anticorpo variou de 1:500 a 1:10000. Em seguida, as membranas foram lavadas com a solução bloqueadora por $1 \mathrm{~h}$ e, posteriormente, incubadas com o segundo anticorpo, conjugado com peroxidase por 1 h, em temperatura ambiente. As bandas foram detectadas após incubação com Luminata (Western Blotting Detection Reagent - Millipore Corporation). A emissão de luz foi detectada e visualizada por fotodocumentador ImageQuant 350 (GE Healthcare Piscata Way, NJ, EUA). A intensidade das bandas foi quantificada por densitometria óptica através da utilização de programa de análise de intensidade de bandas (Image ${ }^{\circledR}$, NIH, USA). Os anticorpos utilizados estão descritos na tabela a seguir: 
Tabela 1 - Anticorpos utilizados nos ensaios de Western blotting.

\begin{tabular}{ccc}
\hline Alvo & Diluição & Marca \\
& & \\
\hline Pro-caspase-1/Caspase-1 & $1: 500$ & Novus Biologicals (NB100-56565F) \\
GAPDH & $1: 10000$ & Sigma-Aldrich (G9545-100UL) \\
$\alpha / \beta$-Tubulina & $1: 4000$ & Cell Signaling Technology (\#2148) \\
\hline
\end{tabular}

\subsection{Quantificação de citocinas por Elisa}

A quantificação da citocina IL-1 $\beta$ no soro foi realizada por método imunoenzimático (ELISA, do inglês Enzyme-Linked ImmunonoSorbent Assay) que se baseia em reações antígeno-anticorpo detectáveis através de reações enzimáticas.

Para obtenção do soro, sangue coletado por punção cardíaca nos animais tratados com veículo e P. Testosterona. O sangue foi centrifugado a $1500 \mathrm{rpm}$ a $4{ }^{\circ} \mathrm{C}$ por $15 \mathrm{~min}$. As amostras de soro foram armazenadas em freezer $-80{ }^{\circ} \mathrm{C}$ até a realização do experimento.

Os ensaios para quantificação de IL-1 $\beta$ foram realizados conforme descrito pelo fabricante dos kits (R\&D Systems, Minneapolis, MN, USA). Em placas de 96 poços foram adicionados $50 \mu \mathrm{L} /$ poço de soluções contendo os anticorpos de captura para cada citocina (anti-IL-1 $\beta$ murino $800 \mathrm{ng} / \mathrm{ml}$ ). Os anticorpos foram diluídos em tampão fosfato salino (PBS) acrescido de $10 \%$ de soro fetal bovino (SFB) e incubados nas placas por $12 \mathrm{~h}$ à $4{ }^{\circ} \mathrm{C}$.

Posteriormente, as placas foram lavadas por três vezes com PBS/Tween-20 (0,05\%). As ligações não específicas foram bloqueadas com $100 \mu \mathrm{L}$ de PBS acrescido de $1 \%$ de BSA, por $120 \mathrm{~min}$, em temperatura ambiente. As amostras e diferentes concentrações de IL-1 $\beta$ para confecção de curva padrão - em volume final de $50 \mu \mathrm{L} /$ poço foram colocadas nas placas e incubadas por $12 \mathrm{~h}$ à $4^{\circ} \mathrm{C}$. 
Após esse período, as placas foram lavadas com PBS/Tween-20 (0,05\%) e $50 \mu \mathrm{L}$ dos anticorpos de detecção biotinilados específicos para cada citocina foram adicionados. Após 1 $\mathrm{h}$, as placas foram lavadas com PBS/Tween-20 (0,05\%) e estreptoavidina-HRP (fornecida pelo fabricante do kit e diluída 1:250) foi adicionada aos poços. Após 30 min de incubação, as placas foram lavadas com PBS/Tween-20 (0,05\%), e $100 \mu \mathrm{L}$ do substrato tetrametilbenzidina - $1 \mathrm{mg} / \mathrm{mL}$, acrescido de 0,06\% de peróxido de hidrogênio, foram colocados em cada poço. As placas foram incubadas por 15 min em temperatura ambiente. A reação foi interrompida com $50 \mu \mathrm{L}$ de ácido sulfúrico $(1 \mathrm{M})$ e a densidade óptica aferida à $450 \mathrm{~nm}$ em espectrofotômetro (FlexStation 3, Molecular Devices, San Jose, CA, USA). Os resultados foram expressos em picogramas/mL.

\subsection{Estudo da geração de espécies reativas de oxigênio}

\subsubsection{Medida da produção de ânion superóxido por Lucigenina}

A geração de ânion superóxido $\left(\mathrm{O}_{2}^{-}\right)$em aortas torácicas foi medida por ensaio de quimioluminescência, utilizando a lucigenina como aceptor de elétrons de dinucleótido de nicotinamida e adenina (NADH) como substrato. O procedimento foi realizado em aortas de camundongos C57/BL6 incubadas com testosterona $\left(10^{-6} \mathrm{M}\right.$ por $\left.2 \mathrm{~h}\right)$ as quais foram

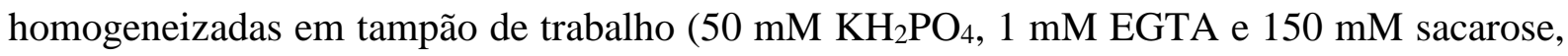
$\mathrm{pH}$ 7.4). Os ensaios foram realizados com $100 \mu \mathrm{l}$ de amostra, lucigenina $(5 \mu \mathrm{M}), \mathrm{NADH}(0,1$ $\mathrm{mM}$ ) e tampão de trabalho. A geração de $\mathrm{O}_{2}^{-}$foi expressa em unidades relativas de luminescência pelo peso seco do tecido em relação à intensidade do controle.

\subsubsection{Dihidroetidina}

A geração de EROs foi determinada utilizando-se também método qualitativo que envolve a dihidroetidina (DHE), precursor não fluorescente do brometo de etídio, conforme previamente descrito por Suzuki e colaboradores (1995). Na presença de EROs, a hidroetidina 
é oxidada no interior da célula, produzindo os compostos fluorescentes etídeo (E) e 2-hidróxi etídeo (EHO), que possuem afinidade pelo DNA nuclear.

Aortas de camundongos C57/BL6 tratados com propionato de testosterona (10 mg/kg por 30 dias) foram isoladas e rapidamente imersas em meio de congelamento. Utilizando-se um criostato (Leica, Alemanha), cortes transversais de aorta $(5 \mu \mathrm{m})$ foram obtidos e colocados em lâminas silanizadas. Os cortes foram incubados com $20 \mu \mathrm{L}$ de dihidroetidina 2,5 $\mu \mathrm{M}\left(30 \mathrm{~min}, \mathrm{a}^{\circ} 7^{\circ} \mathrm{C}\right)$ em câmara úmida e protegidos da luz. Após este período, as lâminas foram observadas em microscópio óptico (ZEISS) equipado com filtro para rodamina e câmera fotográfica, utilizando-se objetiva para fluorescência com aumento de 200X. A localização da geração de EROs foi realizada visualmente, observando-se núcleos marcados com fluorescência vermelha proveniente dos produtos de oxidação da DHE. A geração de EROs foi quantificada através da densidade luminosa corrigida pela área utilizando o programa ImageJ (National Institutes of Heath).

\subsection{Análise estatística}

Os resultados dos experimentos moleculares foram analisados pelo teste $\mathrm{t}$ de Student, teste de análise de variância uma (One-way ANOVA) $e$ de duas vias (Two-way ANOVA), seguido do pós-teste Bonferroni. Em resultados de reatividade vascular, as curvas concentração-efeito individuais foram plotadas em uma curva sigmoidal por análise de regressão não linear. Estas curvas, por sua vez, fornecem o valor de $p \mathrm{D}_{2}$ (logaritmo negativo dos valores de $\mathrm{EC}_{50}$ - concentração que produz $50 \%$ da resposta máxima) e a resposta máxima. Os valores de $p \mathrm{D}_{2}$ e de resposta máxima foram comparados por meio da ANOVA seguida do teste de Bartlett para a homogeneidade das variâncias e teste de múltiplas comparações Bonferroni. O programa Prisma, versão 5.0 (GraphPad Software Inc., San. Diego, CA, USA) foi utilizado para analisar estes parâmetros. Os resultados foram expressos 
como média \pm erro padrão da média (E.P.M.). O nível de significância mínima aceitável foi $\mathrm{p}<0,05$. 
5. Resultados 
5.1 Efeitos da incubação com testosterona sobre as respostas contrátil à fenilefrina e dilatadora à acetilcolina em aortas torácicas de camundongos

$\mathrm{Na}$ avaliação da reatividade vascular, fenilefrina induziu maior resposta contrátil, de modo concentração-dependente, em anéis de aortas incubados com testosterona $\left(10^{-6} \mathrm{M}\right.$ por 2 h), quando comparada àquela em anéis incubados com veículo (Figuras 2A e 2B). Além disso, a vasodilatação dependente do endotélio, mediada por acetilcolina, foi menor em anéis de aorta incubados com testosterona, quando comparada àquela em anéis incubados com veículo (Figuras 2C e 2D). A tabela 2 mostra os efeitos da incubação de aortas torácicas de camundongos com testosterona sobre os valores de $p \mathrm{D}_{2}$ da fenilefrina e acetilcolina. 
A

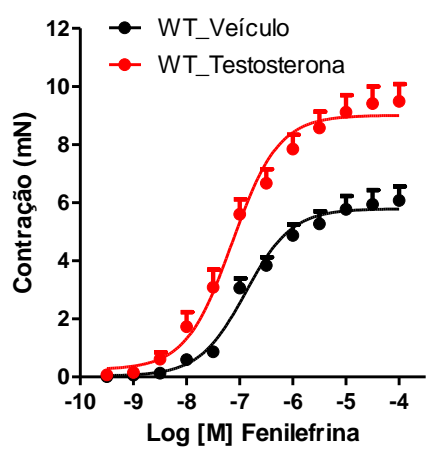

C

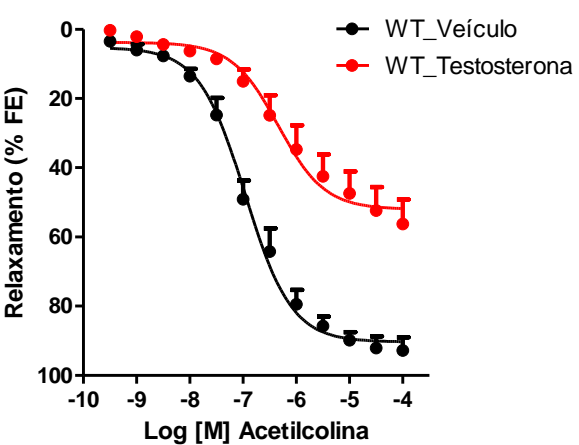

B

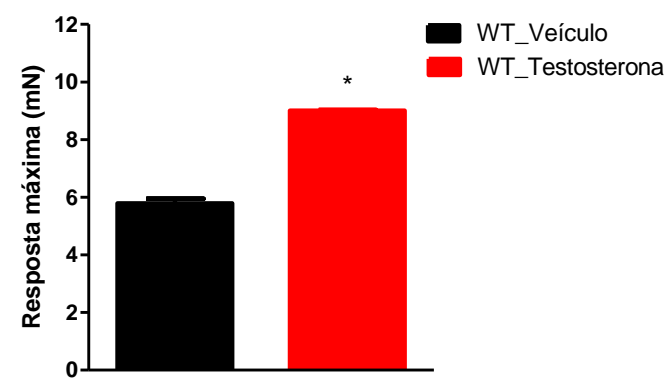

D

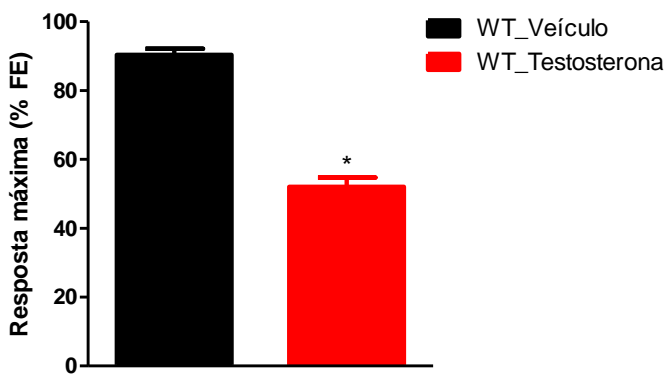

Figura 2 - A incubação de aortas torácicas de camundongos C57BL/6J com testosterona promove disfunção vascular. Curvas concentração-efeito e resposta máxima para fenilefrina (A e B) e acetilcolina $(\mathrm{C}$ e D) em aortas torácicas de camundongos C57BL/6J. Curvas realizadas na presença de testosterona $\left(10^{-6} \mathrm{M}\right.$ por $\left.2 \mathrm{~h}\right)$ ou veículo. Dados expressos como média \pm E.P.M. *, p $<0,05 v s$. WT_Veículo. N=6-7 para cada grupo experimental. Teste $t$ de Student. WT: (Wild type Camundongos do tipo selvagens).

Tabela 2 - Valores de $p D_{2}$ para e acetilcolina em aortas torácicas provenientes de camundongos C57BL/6J wild type incubadas com testosterona e/ou veículo. $p \mathbf{D}_{2}$

\begin{tabular}{lll}
\hline Grupos & WT_Veículo & WT_Testosterona
\end{tabular}

\begin{tabular}{lcc}
\hline Fenilefrina & $6,9 \pm 0,08$ & $7,2 \pm 0,08$ \\
Acetilcolina & $7,0 \pm 0,06$ & $6,3 \pm 0,15^{*}$ \\
\hline
\end{tabular}

Dados expressos como média \pm E.P.M. *, p $<0,05$ vs. WT_Veículo. N=7-10 para cada grupo experimental. Teste $t$ de Student. WT: (Wild type-Camundongos do tipo selvagens). 


\subsection{Efeitos do tratamento de camundongos com propionato de testosterona nas respostas}

de aortas torácicas a fenilefrina e acetilcolina

Para determinar se, de fato, altos níveis de testosterona promovem disfunção vascular, camundongos C57BL/6J foram tratados com propionato de testosterona $(10 \mathrm{mg} / \mathrm{kg}$ por 30 dias). O tratamento elevou, a níveis suprafisiológicos, a concentração plasmática de testosterona total (Figura 3A). Além disso, camundongos C57BL/6J tratados com propionato de testosterona (10 mg/kg por 30 dias) apresentaram aumento na massa corporal (Figura 3B). $\mathrm{Na}$ avaliação da reatividade vascular, a fenilefrina induziu maior resposta contrátil, de modo concentração-dependente, nos anéis de aortas dos camundongos tratados com propionato de testosterona, quando comparada àquela em camundongos tratados com veículo (Figuras 3C e 3D). Além disso, a vasodilatação dependente do endotélio, mediada pela acetilcolina, foi menor em anéis de aortas de camundongos tratados com propionato de testosterona, quando comparada àquela em aortas de camundongos tratados com veículo (Figuras $3 \mathrm{E}$ e $3 \mathrm{~F}$ ). A tabela 3 mostra os efeitos do tratamento de camundongos com propionato de testosterona sobre os valores de $p \mathrm{D}_{2}$ da fenilefrina e acetilcolina em aortas torácicas. 

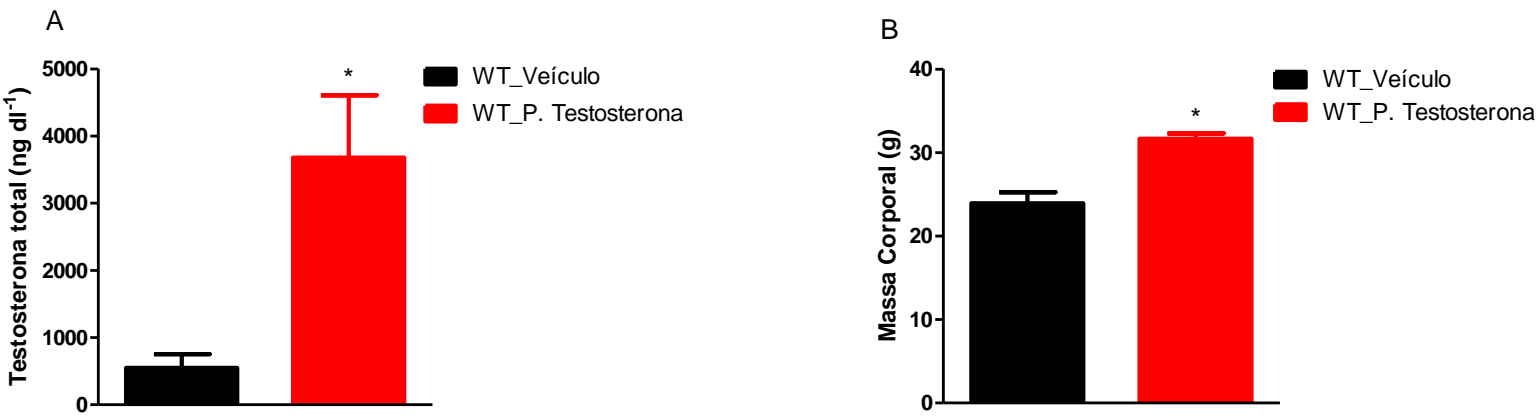

C

D
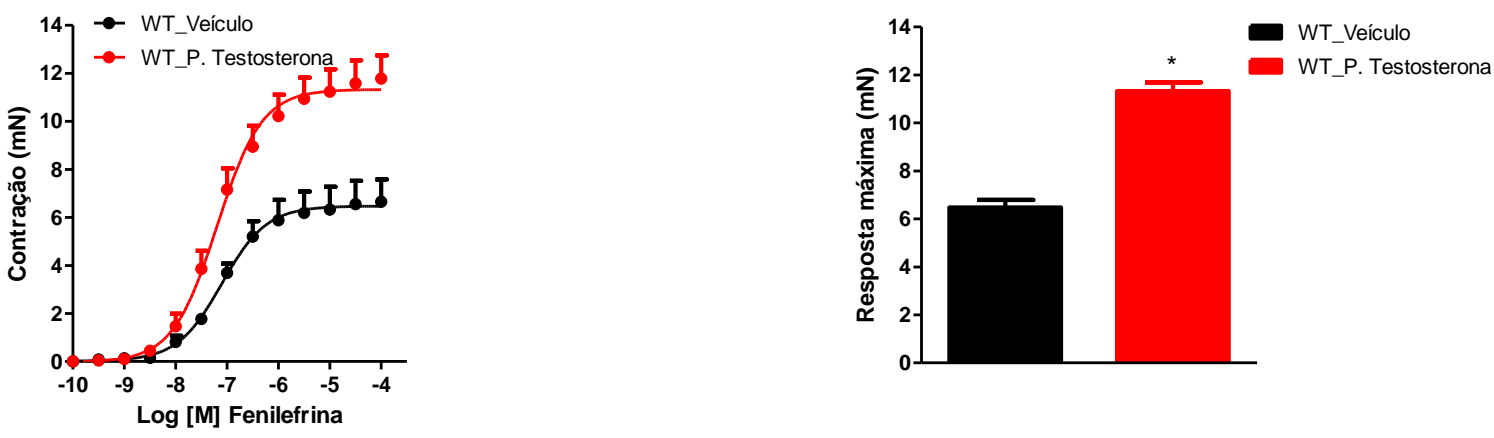

F
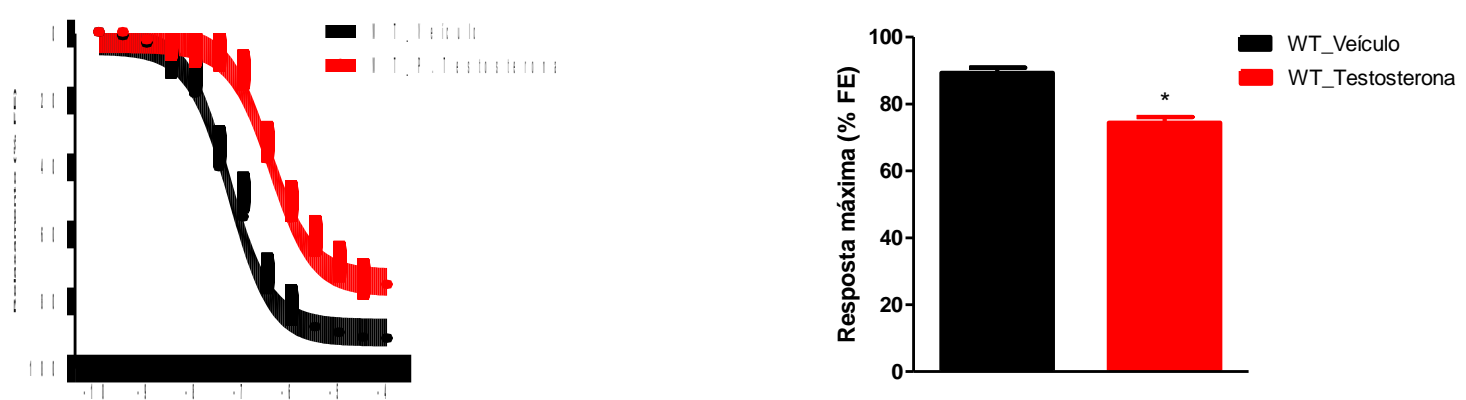

Figura 3 - $O$ tratamento de camundongos C57BL/6J com propionato de testosterona promove disfunção vascular. Níveis de testosterona (A), massa corporal (B), curvas concentração-efeito e resposta máxima para fenilefrina $(\mathrm{C}$ e $\mathrm{D})$ e acetilcolina $(\mathrm{E}$ e $\mathrm{F})$ em aortas torácicas de camundongos C57BL/6J tratados com propionato de testosterona $(10 \mathrm{mg} / \mathrm{kg}$ por 30 dias) ou veículo. Dados expressos como média \pm E.P.M. * ${ }^{*}$ p $<0,05$ vs. WT_Veículo. N=6-7 para cada grupo experimental. Teste $t$ de Student. WT: (Wild type - Camundongos do tipo selvagens). 
Tabela 3 - Valores de $p D_{2}$ para fenilefrina e acetilcolina em aortas torácicas

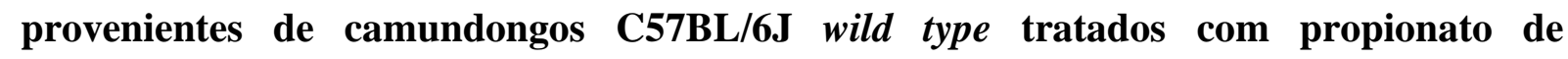
testosterona e/ou veículo.

$$
\text { pD2 }
$$

\begin{tabular}{lcc}
\hline Grupos & WT_Veículo & WT_P. Testosterona \\
\hline Fenilefrina & $7,0 \pm 0,13$ & $7,2 \pm 0,09$ \\
Acetilcolina & $7,3 \pm 0,06$ & $6,4 \pm 0,06^{*}$ \\
\hline
\end{tabular}

Dados expressos como média \pm E.P.M. *, p $<0,05$ vs. WT_Veículo. N=5-7 para cada grupo experimental. Teste $t$ de Student. WT: (Wild type - Camundongos do tipo selvagens). 


\subsection{Contribuição dos receptores para andrógenos na disfunção vascular induzida pela}

incubação com testosterona

Para determinar se os receptores para andrógenos contribuem para disfunção vascular induzida pela testosterona, foi utilizada flutamida [antagonista de receptor para andrógeno $\left(10^{-5} \mathrm{M}\right.$ por $\left.\left.30 \mathrm{~min}\right)\right]$. A flutamida preveniu o aumento da resposta contrátil à fenilefrina (Figuras 4A e 4B), e o comprometimento da vasodilatação a acetilcolina (Figuras 4C e 4D). Não foram observadas diferenças na função vascular entre anéis de aortas torácicas de camundongos C57BL/6J incubados somente com flutamida e anéis de aortas torácicas de camundongos incubados com veículo. A tabela 4 mostra os efeitos da flutamida sobre os valores de $p \mathrm{D}_{2}$ da fenilefrina e acetilcolina em anéis de aortas torácicas de camundongos incubados com testosterona. 

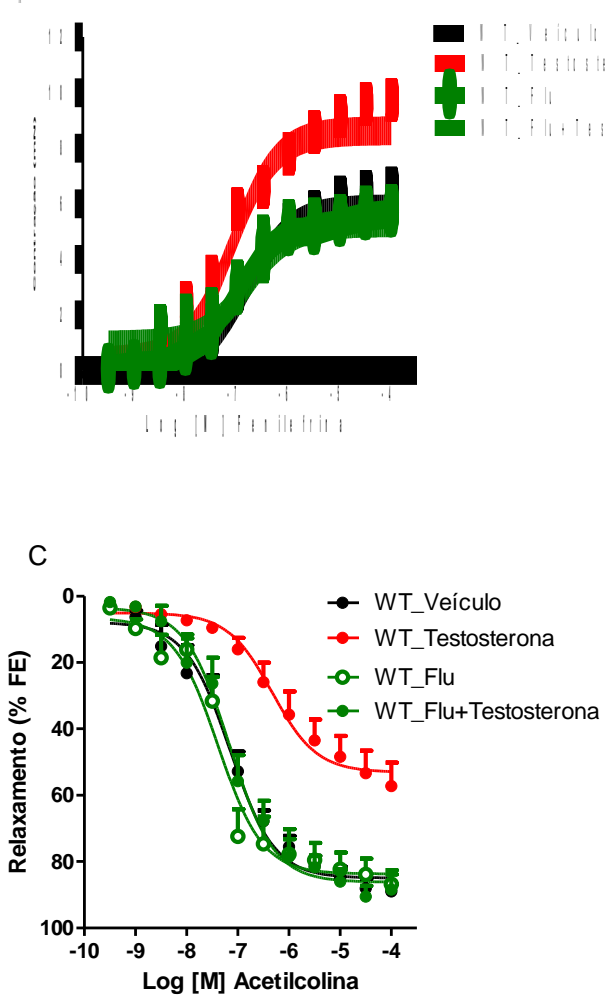

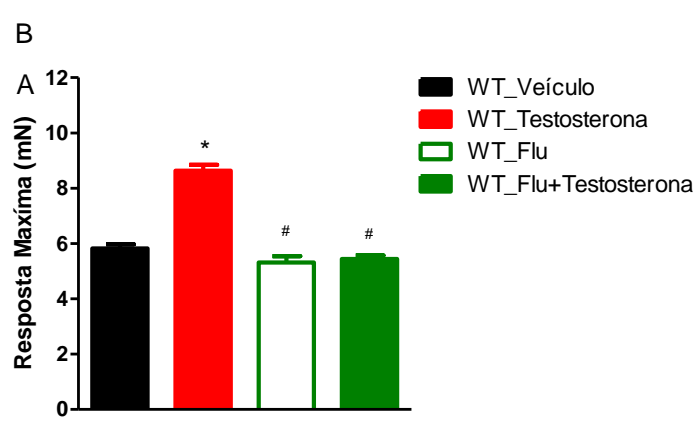

D

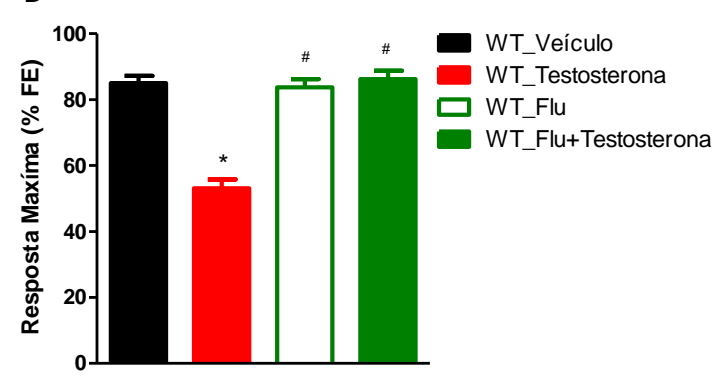

Figura 4 - A testosterona induz disfunção vascular via ativação de receptores para andrógeno. Curvas concentração-efeito e resposta máxima para fenilefrina (A e B) e acetilcolina (C e D) em aortas torácicas de camundongos C57BL/6J incubadas com testosterona $\left(10^{-6} \mathrm{M}\right.$ por $\left.2 \mathrm{~h}\right)$ em presença de veículo ou flutamida (antagonista de receptores para andrógeno, $10^{-5} \mathrm{M}$ por $30 \mathrm{~min}$ ). Dados expressos como média \pm E.P.M. *, p $<0,05$ vs. WT_Veículo; \#, p<0,05 vs. WT_Testosterona. N=4-10 para cada grupo experimental. One Way ANOVA. WT: (Wild type - Camundongos do tipo selvagens).

Tabela 4 - Valores de $p \mathrm{D}_{2}$ para fenilefrina e acetilcolina, em presença de veículo e/ou flutamida, em aortas torácicas provenientes de camundongos C57BL/6J wild type incubadas com testosterona.

$$
p \mathbf{D}_{2}
$$

\begin{tabular}{lcccc}
\hline Grupos & WT_Veículo & WT_Testosterona & WT_Flu & $\begin{array}{c}\text { WT_Flu+ } \\
\text { Testosterona }\end{array}$ \\
\hline Fenilefrina & $6,8 \pm 0,08$ & $7,1 \pm 0,08$ & $6,8 \pm 0,12$ & $7,0 \pm 0,07$ \\
Acetilcolina & $7,2 \pm 0,09$ & $6,3 \pm 0,14^{*}$ & $7,2 \pm 0,09^{\#}$ & $7,4 \pm 0,11^{\#}$ \\
\hline
\end{tabular}

Dados expressos como média \pm E.P.M. *, p<0,05 vs. WT_Veículo; \#, p<0,05 vs. WT_Testosterona. $\mathrm{N}=4-10$ para cada grupo experimental. One Way ANOVA. WT: (Wild type - Camundongos do tipo selvagens). 
5.4 Geração vascular de espécies reativas de oxigênio mitocondriais induzida por níveis suprafisiológicos de testosterona

Inicialmente, a geração de EROs em aortas torácicas de camundongos C57BL/6J wild type incubadas com testosterona foi determinada. De fato, testosterona promoveu aumento na geração de EROs (Figura 5A). Além disso, a geração de EROs mitocondriais em aortas torácicas de camundongos tratados com propionato de testosterona também foi determinada. O tratamento com propionato de testosterona aumentou a geração de EROs mitocondriais, efeito este bloqueado pela incubação com CCCP (Figura 5B). 


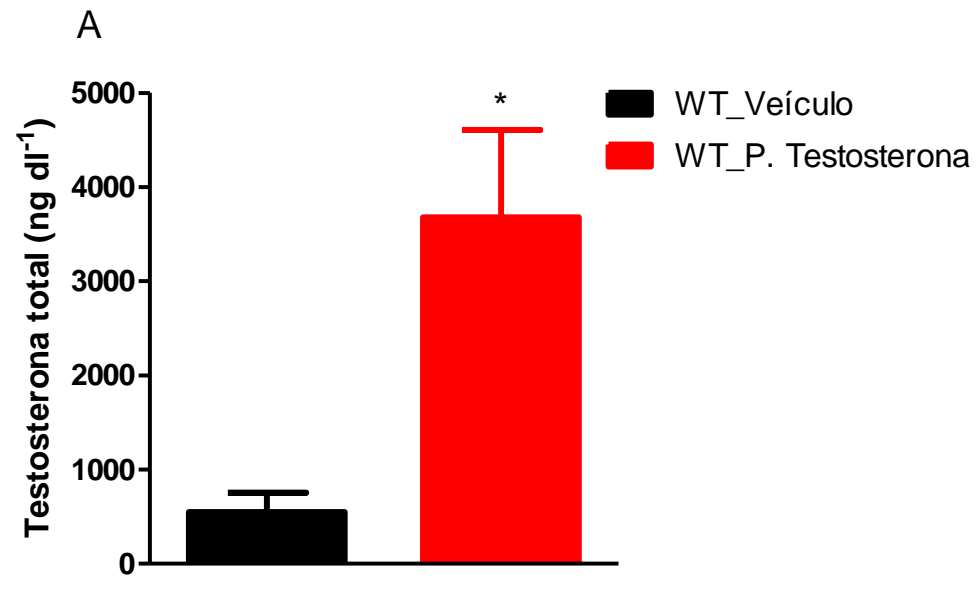

B
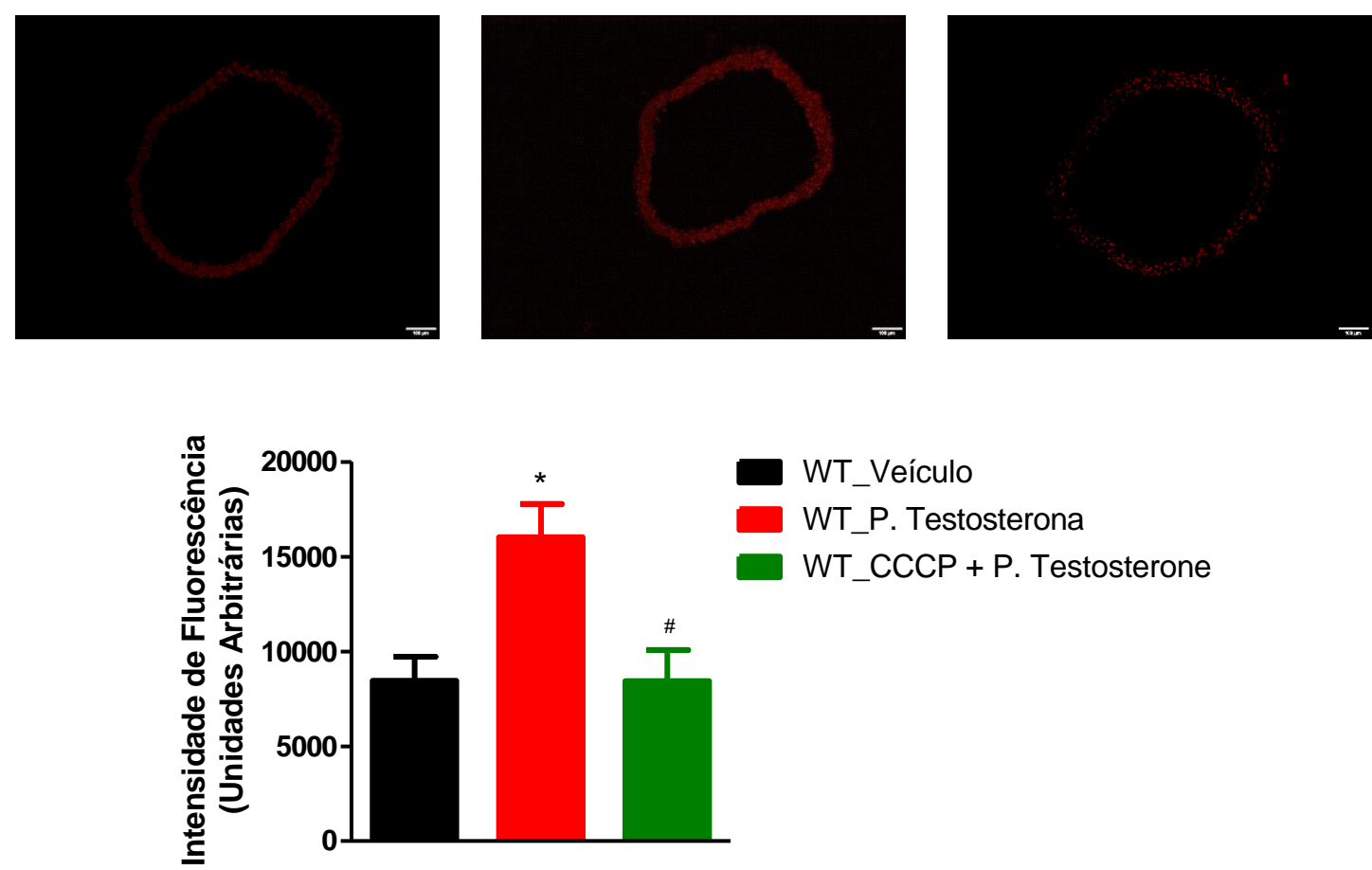

WT_Veículo

WT_P. Testosterona

WT_CCCP + P. Testosterone

Figura 5 - Efeitos dos níveis suprafisiológicos de testosterona na geração vascular de espécies reativas de oxigênio mitocondriais. Níveis de espécies reativas de oxigênio em aortas torácicas de camundongos C57BL/6J incubadas com testosterona $\left(10^{-6} \mathrm{M}\right.$ por $\left.2 \mathrm{~h}\right)$ ou veículo (A). Níveis de espécies reativas de oxigênio em aortas torácicas de camundongos C57BL/6J tratados com propionato de testosterona (10 mg/kg por 30 dias) ou veículo, e CCCP (desacoplador mitocondrial, $10^{-6} \mathrm{M}$ por 30 min (B). Dados expressos como média \pm E.P.M. * ${ }^{*}$ p $<0,05$ vs. WT_Veículo; * $, \mathrm{p}<0,05$ vs. WT_P. Testosterona. N=4-10 para cada grupo experimental. Teste $t$ de Student e One Way ANOVA. WT: (Wild type - Camundongos do tipo selvagens). 


\subsection{Contribuição das espécies reativas de oxigênio mitocondriais para a disfunção vascular induzida pela incubação com testosterona}

Seguindo a hipótese deste estudo, para verificar a participação das EROs mitocondriais nos efeitos promovidos pela incubação com testosterona, os experimentos foram realizados em presença de desacoplador mitocondrial, $\mathrm{CCCP}$, que acelera o fluxo de elétrons na cadeia respiratória e reduz a geração de EROs. Neste contexto, CCCP preveniu o aumento da resposta contrátil à fenilefrina (Figuras 6A e 6B) e o comprometimento do efeito vasodilatador da acetilcolina (Figuras 6C e 6D). A tabela 5 mostra os efeitos de CCCP sobre os valores de $p \mathrm{D}_{2}$ da fenilefrina e acetilcolina em anéis de aortas torácicas de camundongos incubadas com testosterona. Não foram observadas diferenças na função vascular entre anéis de aortas torácicas de camundongos C57BL/6J incubados somente com CCCP e anéis de aortas torácicas de camundongos incubados com veículo. 

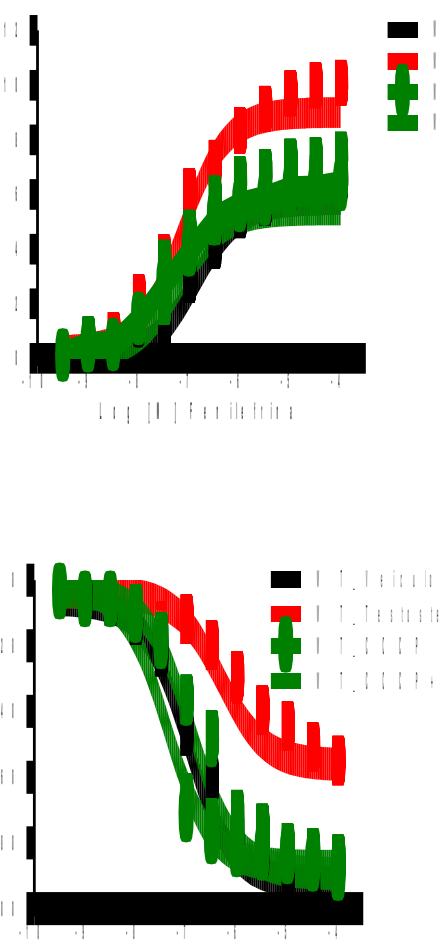
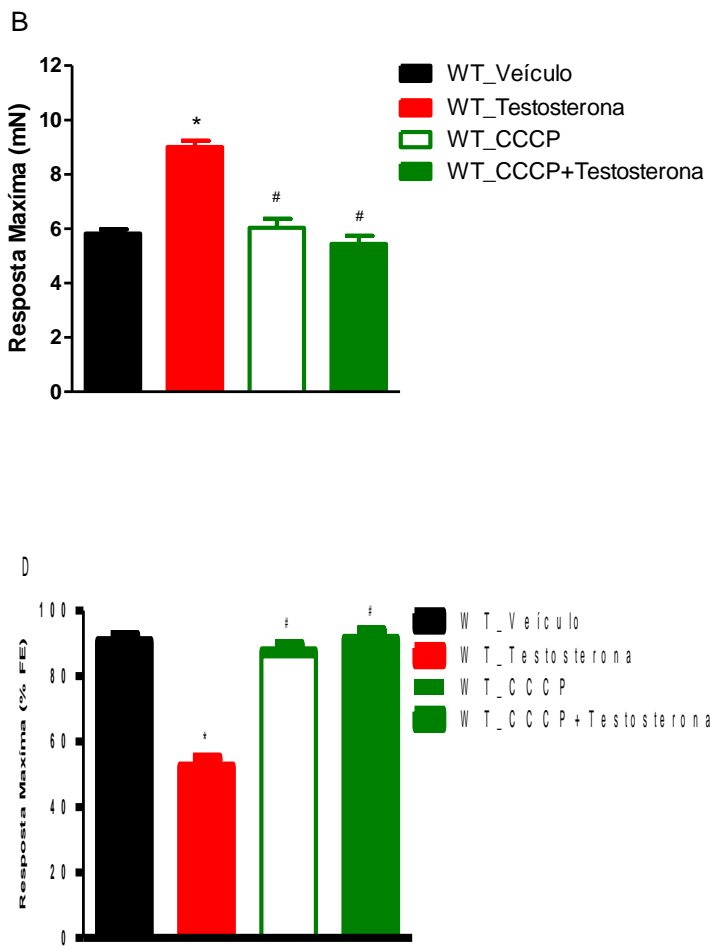

Figura 6 - A testosterona induz disfunção vascular via geração de espécies reativas de oxigênio mitocondriais. Curvas concentração-efeito e resposta máxima para fenilefrina (A e B) e acetilcolina (C e D) em aortas torácicas de camundongos C57BL/6J wild type incubadas com testosterona $\left(10^{-6} \mathrm{M}\right.$ por $2 \mathrm{~h}$ ) e/ou CCCP (desacoplador mitocondrial, $10^{-6} \mathrm{M}$ por $30 \mathrm{~min}$ ). Dados expressos como média \pm E.P.M. *, ${ }^{*}<0,05$ vs. WT_Veículo; \#, $\mathrm{p}<0,05$ vs. WT_Testosterona. $\mathrm{N}=4-10$ para cada grupo experimental. One Way ANOVA. WT: (Wild type - Camundongos do tipo selvagens).

Tabela 5 - Valores de $p \mathrm{D}_{2}$ para fenilefrina e acetilcolina, em presença de veículo e/ou

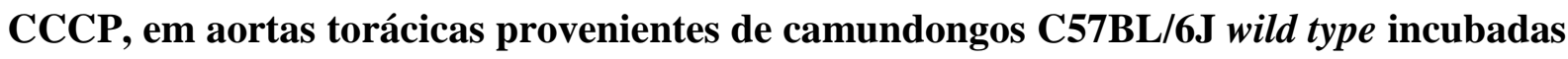
com testosterona.

$$
\text { pD2 }
$$

\begin{tabular}{lcccc}
\hline Grupos & WT_Veículo & WT_Testosterona & WT_CCCP & $\begin{array}{c}\text { WT_CCC+ } \\
\text { Testosterona }\end{array}$ \\
\hline Fenilefrina & $6,8 \pm 0,08$ & $7,1 \pm 0,08$ & $7,2 \pm 0,21$ & $7,2 \pm 0,18$ \\
Acetilcolina & $7,0 \pm 0,06$ & $6,3 \pm 0,13^{*}$ & $7,4 \pm 0,11^{\#}$ & $6,9 \pm 0,10^{\#}$ \\
\hline
\end{tabular}

Dados expressos como média \pm E.P.M. *, p $<0,05$ vs. WT_Veículo; \#, $<<0,05$ vs. WT_Testosterona. $\mathrm{N}=4-9$ para cada grupo experimental. One Way ANOVA. WT: (Wild type - Camundongos do tipo selvagens). 


\subsection{Contribuição do inflamassoma NLRP3 para a disfunção vascular induzida pela incubação com testosterona}

Inicialmente, a contribuição do inflamassoma NLRP3 sobre a disfunção vascular induzida pela incubação com testosterona foi avaliada utilizando-se o inibidor seletivo de NLRP3, MCC950 (Coll et al., 2015). Nesse contexto, MCC950 preveniu o aumento da resposta contrátil à fenilefrina (Figuras 7A e 7B) e preveniu parcialmente o comprometimento da vasodilatação induzida por acetilcolina (Figuras 7C e 7D). A tabela 6 mostra os efeitos da flutamida sobre os valores de $p \mathrm{D}_{2}$ da fenilefrina e acetilcolina em anéis de aortas torácicas de camundongos incubadas com testosterona.

Além disso, anéis de aortas torácicas de camundongos knockouts para NLRP3 foram incubados com testosterona. A deleção de NLRP3 preveniu completamente o aumento da resposta contrátil à fenilefrina (Figuras $8 \mathrm{~A}$ e $8 \mathrm{~B}$ ) e $\mathrm{o}$ comprometimento do efeito vasodilatador da acetilcolina (Figuras 8C e 8D) induzidos pela testosterona. A tabela 7 mostra os efeitos da deleção de NLRP3 sobre os valores de $p \mathrm{D}_{2}$ da fenilefrina e acetilcolina em anéis de aortas torácicas de camundongos incubados com testosterona. Anéis de aortas torácicas de camundongos knockouts para NLRP3 incubados com veículo não mostraram alterações na função vascular, quando comparados com anéis de aortas torácicas de camundongos C57BL/6J wild type incubados com veículo. 


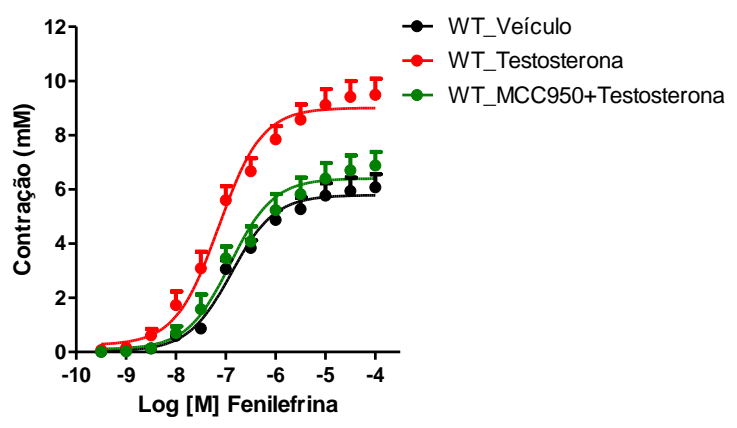

C

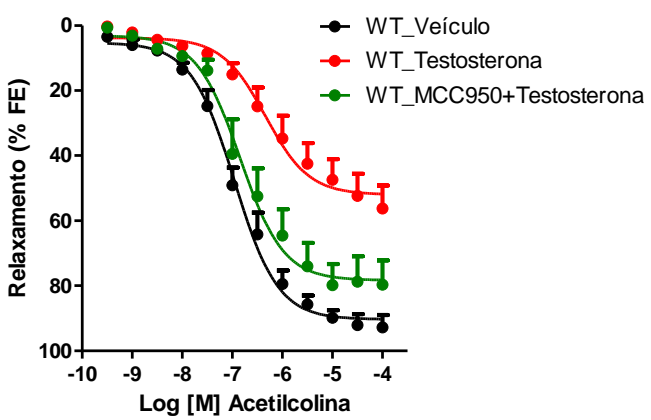

B

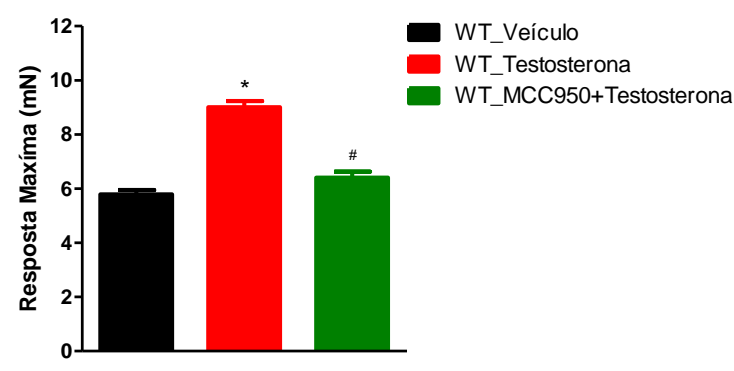

D

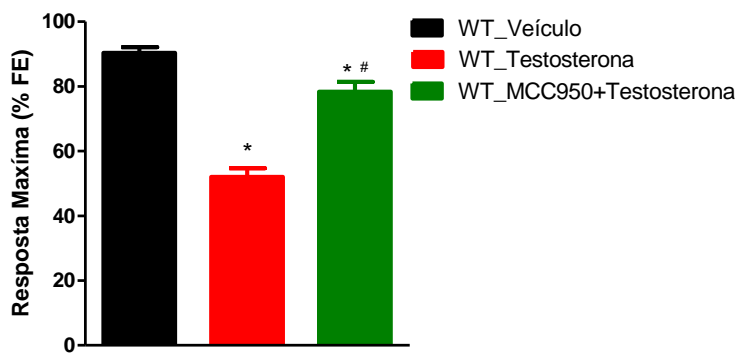

Figura 7 - A testosterona induz disfunção vascular via inflamassoma NLRP3. Curvas concentração-efeito e resposta máxima para fenilefrina (A e B) e acetilcolina (C e D) em aortas torácicas de camundongos C57BL/6J incubadas com testosterona $\left(10^{-6} \mathrm{M}\right.$ por $\left.2 \mathrm{~h}\right)$ em presença de veículo ou MCC950 (inibidor de NLRP3, 10-6 M por $30 \mathrm{~min}$ ). Dados expressos como média \pm E.P.M. *, $\mathrm{p}<0,05$ vs. WT_Veículo; ${ }^{\#}, \mathrm{p}<0,05$ vs. WT_Testosterona. $\mathrm{N}=5-10$ para cada grupo experimental. One Way ANOVA. WT: (Wild type - Camundongos do tipo selvagens).

Tabela 6 - Valores de $p \mathrm{D}_{2}$ para fenilefrina e acetilcolina, em presença de veículo e/ou MCC950, em aortas torácicas provenientes de camundongos C57BL/6J wild type incubadas com testosterona.

\section{$p \mathbf{D}_{2}$}

\begin{tabular}{lccc}
\hline Grupos & WT_Veículo & WT_Testosterona & $\begin{array}{c}\text { WT_MCC950 } \\
\text { Testosterona }\end{array}$ \\
\hline Fenilefrina & $6,9 \pm 0,08$ & $7,1 \pm 0,08$ & $6,9 \pm 0,10$ \\
Acetilcolina & $7,0 \pm 0,06$ & $6,3 \pm 0,14^{*}$ & $6,8 \pm 0,12^{\#}$ \\
\hline
\end{tabular}

Dados expressos como média \pm E.P.M. *, p $<0,05$ vs. WT_Veículo; \#, p $<0,05$ vs. WT_Testosterona. $\mathrm{N}=5-10$ para cada grupo experimental. One Way ANOVA. WT: (Wild type - Camundongos do tipo selvagens). 
A
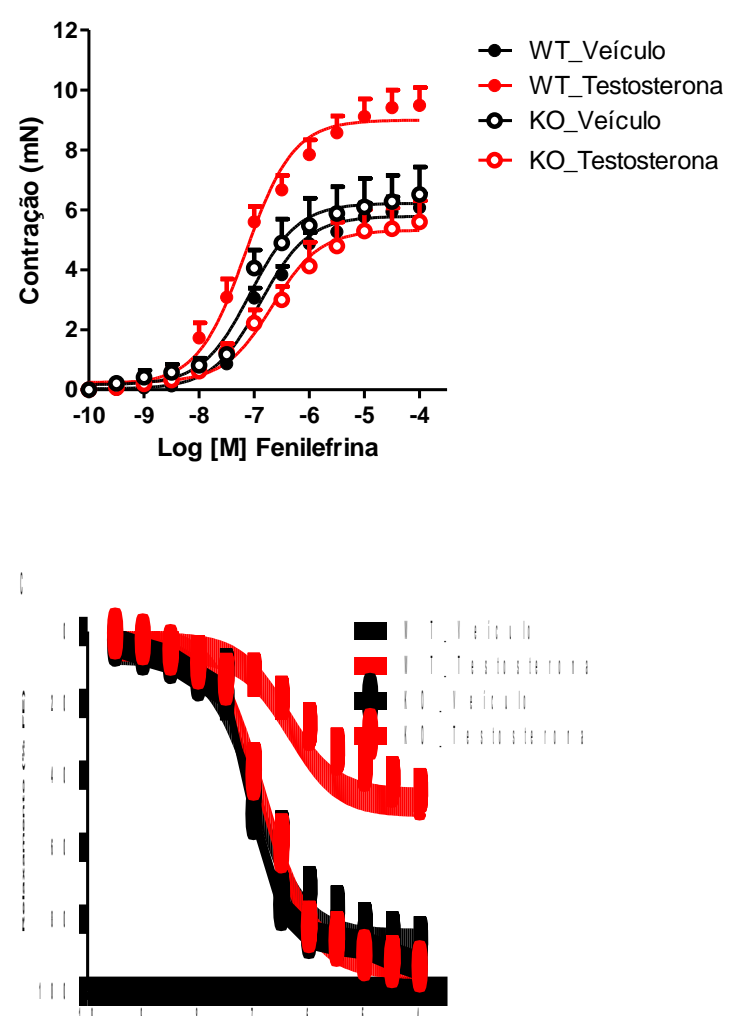
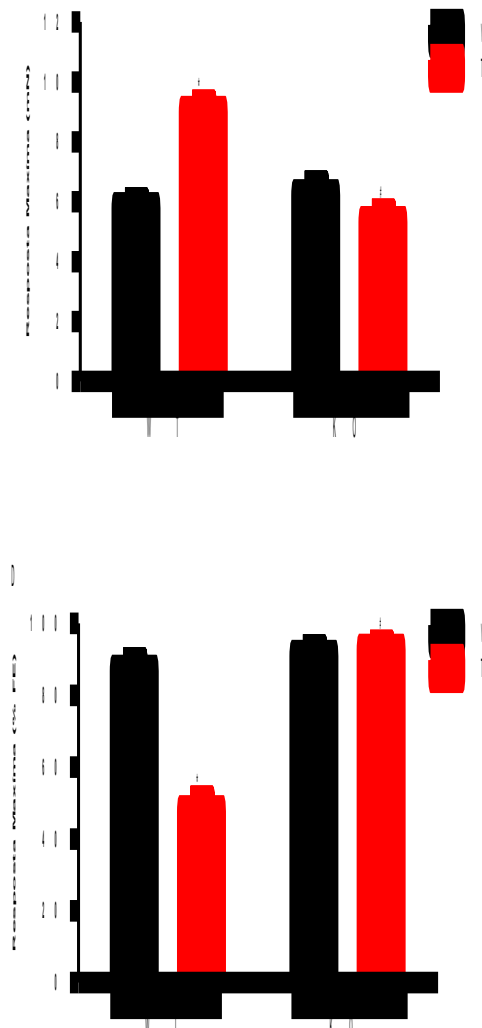

Figura 8 - A testosterona induz disfunção vascular via inflamassoma NLRP3. Curvas concentração-efeito e resposta máxima para fenilefrina (A e B) e acetilcolina (C e D) em aortas torácicas de camundongos C57BL/6J wild type e knockouts $(\mathrm{KO})$ para NLRP3 incubadas com testosterona $\left(10^{-6} \mathrm{M}\right.$ por $\left.2 \mathrm{~h}\right)$ ou veículo. Dados expressos como média \pm E.P.M. ${ }^{*}, \mathrm{p}<0,05$ vs. WT_Veículo; \#, $\mathrm{p}<0,05$ vs. WT_Testosterona. N=4-10 para cada grupo experimental. Two Way ANOVA. WT: (Wild type - Camundongos do tipo selvagens).

Tabela 7 - Valores de $p D_{2}$ para fenilefrina e acetilcolina em aortas torácicas provenientes de camundongos C57BL/6J wild type e knockouts para NLRP3 incubadas com testosterona e/ou veículo.

$$
p \mathbf{D}_{2}
$$

\begin{tabular}{lcccc}
\hline Grupos & WT_Veículo & WT_Testosterona & KO_Veículo & KO_Testosterona \\
\hline Fenilefrina & $6,8 \pm 0,08$ & $7,1 \pm 0,07$ & $7,0 \pm 0,14$ & $6,8 \pm 0,13$ \\
Acetilcolina & $7,0 \pm 0,07$ & $6,4 \pm 0,16^{*}$ & $7,0 \pm 0,06$ & $6,8 \pm 0,04^{\#}$
\end{tabular}

Dados expressos como média \pm E.P.M. *, p<0,05 vs. WT_Veículo; \#, p $<0,05$ vs. WT_Testosterona. $\mathrm{N}=4-10$ para cada grupo experimental. Two Way ANOVA. WT: (Wild type - Camundongos do tipo selvagens). 


\subsection{Contribuição do inflamassoma NLRP3 para a disfunção vascular induzida pelo tratamento de camundongos com propionato de testosterona}

Camundongos knockouts para NLRP3 também foram tratados com propionato de testosterona. O tratamento aumentou, a níveis suprafisiológicos, a concentração plasmática de testosterona livre (Figura 9A). Além disso, os camundongos C57BL/6J wild type e knockouts tratados com propionato de testosterona $(10 \mathrm{mg} / \mathrm{kg}$ por 30 dias $)$ apresentaram aumento na massa corporal (Figura 9B). Na avaliação da reatividade vascular, a deleção de NLRP3 preveniu o aumento da resposta contrátil à fenilefrina (Figuras 9C e 9D) e $\mathrm{o}$ comprometimento do efeito vasodilatador da acetilcolina (Figuras 9E e 9F) induzidos pelo tratamento com propionato de testosterona. A tabela 8 mostra os efeitos da deleção de NLRP3 sobre os valores de $p \mathrm{D}_{2}$ da fenilefrina e acetilcolina em anéis de aortas torácicas de camundongos tratados com propionato de testosterona. Camundongos knockouts para NLRP3 tratados com veículo não apresentaram alterações na função vascular, comparados com camundongos wild type tratados com veículo. 

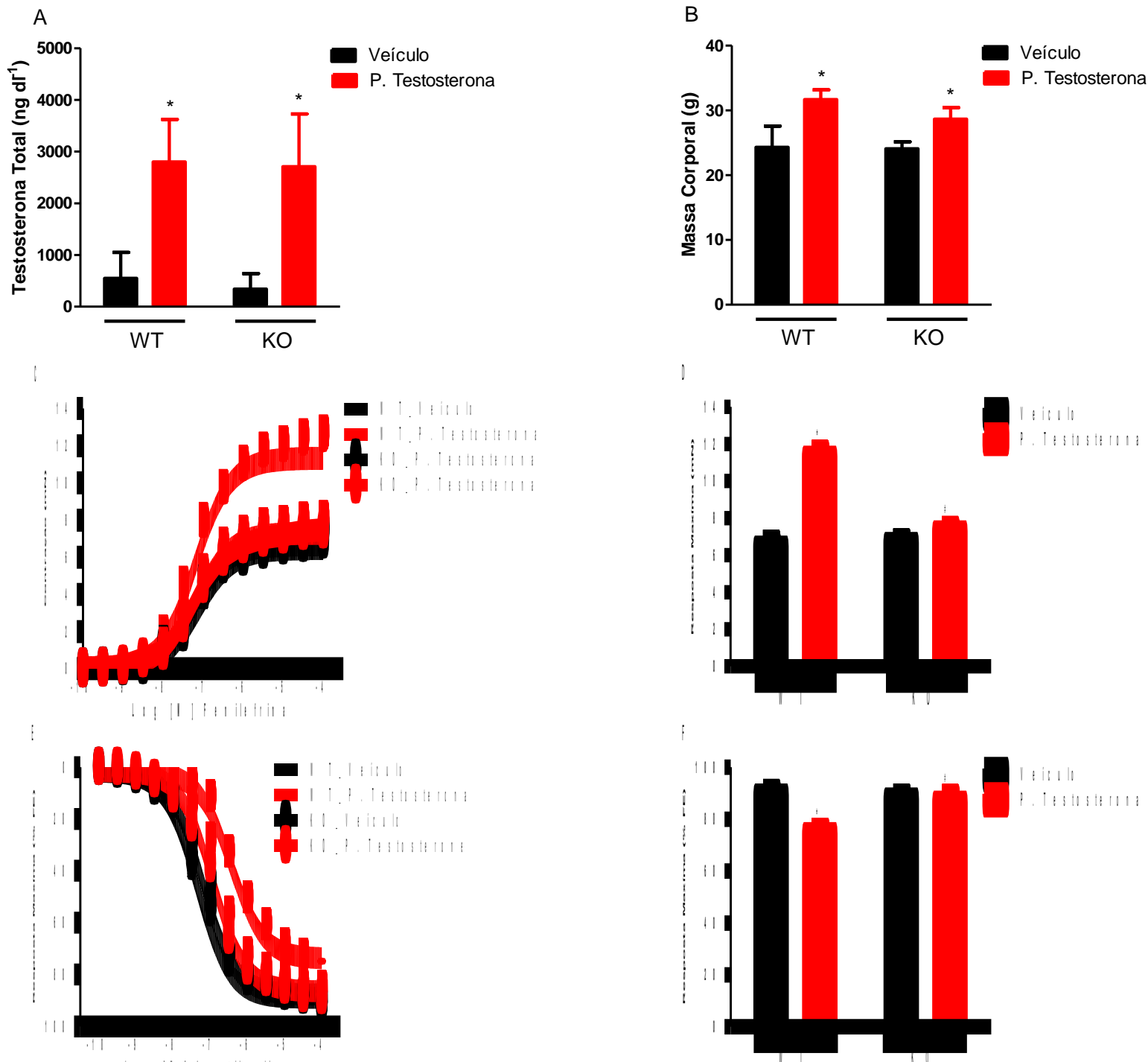

Figura 9 - O propionato de testosterona induz disfunção vascular via inflamassoma NLRP3.

Níveis de testosterona (A), massa corporal (B), curvas concentração-efeito e resposta máxima para fenilefrina (C e D) e acetilcolina (E e F) em aortas torácicas de camundongos C57BL/6J wild type e knockouts (KO) para NLRP3 tratados com propionato de testosterona (10 mg/kg por 30 dias) ou veículo. Dados expressos como média \pm E.P.M. *, p $<0,05$ vs. WT_Veículo; \#, p<0,05 vs. WT_P. Testosterona. N=5-7 para cada grupo experimental. Two Way ANOVA. WT: (Wild type Camundongos do tipo selvagens). 
Tabela 8 - Valores de $p \mathrm{D}_{2}$ para fenilefrina e acetilcolina em aortas torácicas provenientes de camundongos C57BL/6J wild type e knockouts para NLRP3 tratados com propionato de testosterona e/ou veículo.

$$
p \mathbf{D 2}
$$

\begin{tabular}{lcccc}
\hline Grupos & WT_Veículo & $\begin{array}{c}\text { WT_P. } \\
\text { Testosterona }\end{array}$ & KO_Veículo & $\begin{array}{c}\text { KO_P. } \\
\text { Testosterona }\end{array}$ \\
\hline Fenilefrina & $7,1 \pm 0,15$ & $7,2 \pm 0,09$ & $7,2 \pm 0,09$ & $7,2 \pm 0,10$ \\
Acetilcolina & $7,3 \pm 0,06$ & $6,4 \pm 0,06^{*}$ & $7,2 \pm 0,06$ & $6,9 \pm 0,09^{\#}$ \\
\hline
\end{tabular}

Dados expressos como média \pm E.P.M. *, p $<0,05$ vs. WT_Veículo; ${ }^{\#}, \mathrm{p}<0,05 v s$. WT_P. Testosterona. $\mathrm{N}=5-7$ para cada grupo experimental. Two Way ANOVA. WT: (Wild type - Camundongos do tipo selvagens). 


\subsection{Avaliação dos componentes do inflamassoma NLRP3 em modelo experimental com}

níveis suprafisiológicas de testosterona

Componentes que indicam ativação do inflamassoma NLRP3 foram avaliados nos dois modelos aqui descritos, incubação in vitro com testosterona e tratamento in vivo com propionato de testosterona. Inicialmente, a ativação da caspase-1 foi avaliada. Anéis de aortas torácicas incubadas com testosterona apresentaram aumento na ativação de caspase-1 (Figura 10A). Resultado similar foi encontrado em anéis de aortas torácicas de camundongos tratados com propionato de testosterona (Figura 10B). Preliminarmente, os níveis de IL-1 $\beta$ foram avaliados no soro de camundongos tratados com propionato de testosterona, sugerindo-se aumento nos níveis circulantes de IL-1 $\beta$ após o tratamento (Figura 10C). 
A
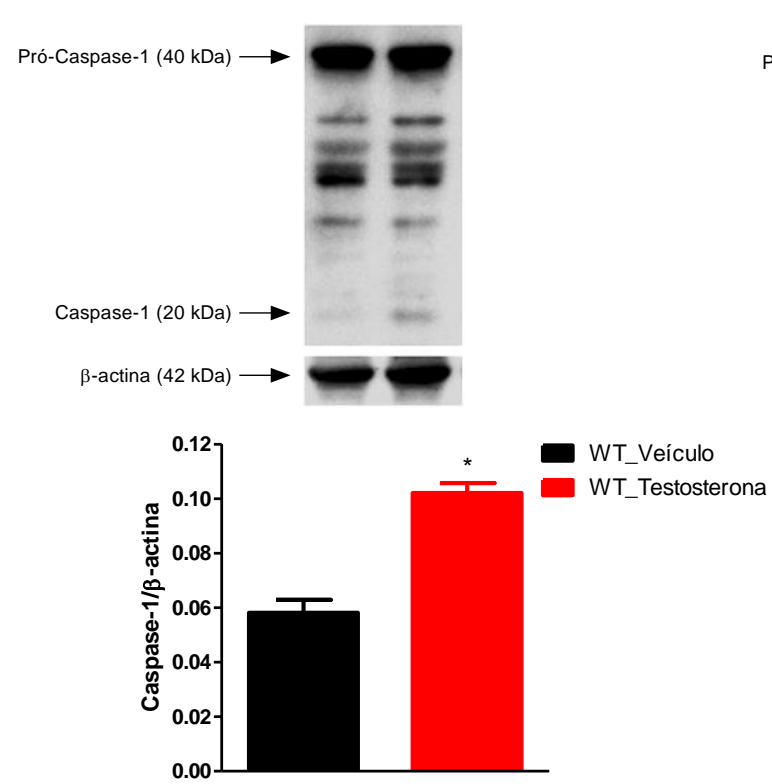

C

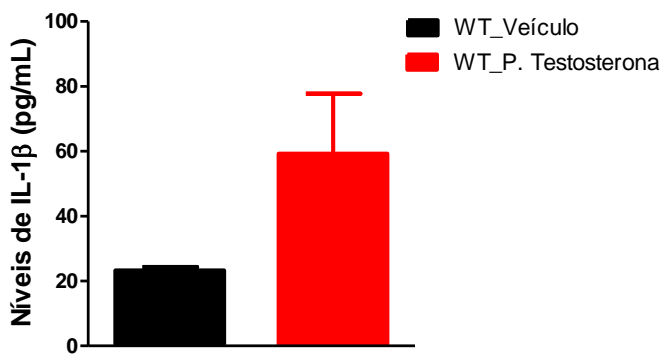

B

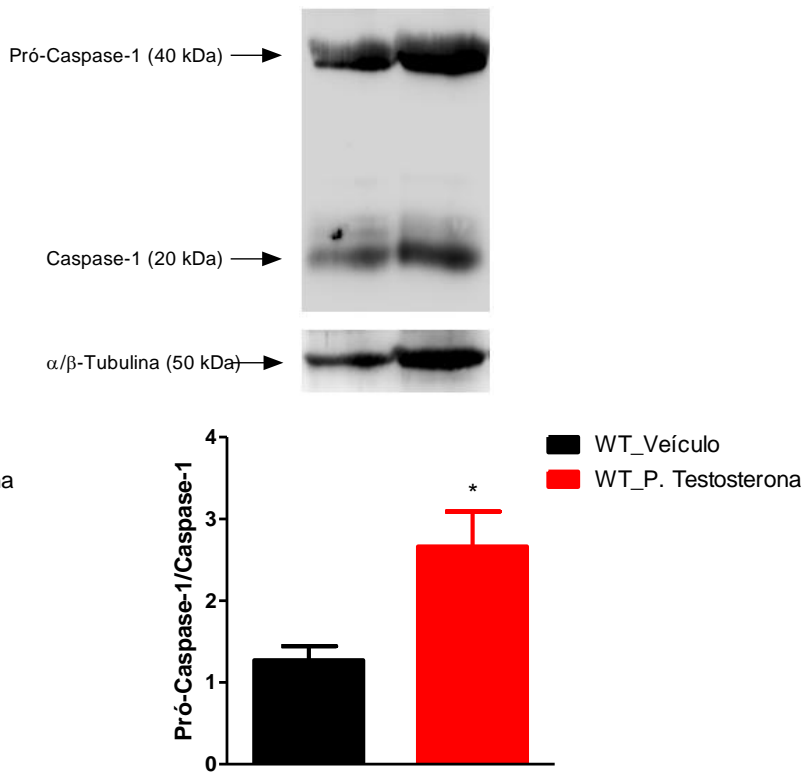

Figura 10 - A incubação de aortas torácicas com testosterona e tratamento de camundongos C57BL/6J wild type com propionato de testosterona induzem aumento de componentes que indicam ativação do inflamassoma NLRP3. Expressão de Caspase-1 em aortas torácicas de camundongos C57BL/6J incubadas com testosterona $-10^{-6} \mathrm{M}$ por $2 \mathrm{~h}$, (A) ou veículo; e em aortas torácicas de camundongos C57BL/6J tratados com propionato de testosterona $-10 \mathrm{mg} / \mathrm{kg}$ por 30 dias, (B) ou veículo. (C), Níveis de IL-1 $\beta$ no soro de camundongos tratados com propionato de testosterona ou veículo. Dados expressos como média \pm E.P.M. *, p<0,05 vs. WT_Veículo. N= 3-6 para cada grupo experimental. Teste $t$ de Student. WT: (Wild type - Camundongos do tipo selvagens). 
6. Discussão 
Atualmente, vários estudos demonstram que mecanismos deflagrados por componentes neurais e endócrinos podem justificar o risco cardiovascular em diversas doenças, tais como diabetes, obesidade hipertensão arterial e aterosclerose. Neste contexto, a testosterona, um andrógeno anabólico predominantemente masculino, está associado não apenas ao controle do metabolismo sistêmico, mas também ao controle do tônus vascular e da função cardíaca (Phillips, 1993). Os experimentos realizados neste estudo elucidaram os efeitos extragonadais da testosterona em um contexto de disfunção vascular associada à níveis suprafisiológicos deste hormônio. Os principais achados evidenciam uma associação íntima entre testosterona, estresse oxidativo, inflamação e disfunção vascular.

Inicialmente, buscamos a compreensão de quais seriam os efeitos agudos de altas concentrações de testosterona sob a função vascular. Desta forma, anéis de aorta torácica foram incubados com testosterona. De fato, nesta condição a testosterona promoveu aumento da contração induzida por fenilefrina e diminuição da vasodilatação induzida por acetilcolina, eventos avaliados pela realização de curvas concentração-efeito para fenilefrina, agonista alfaadrenérgico e, acetilcolina, agonista de receptores muscarínicos, respectivamente. Teoh e colaboradores demonstraram que a incubação de anéis da artéria coronária com testosterona potencializa significativamente a vasoconstrição mediada por endotelina-1 e também por U46619, análogo do tromboxano (Teoh et al., 2000). Muito embora haja raros relatos na literatura sobre altas concentrações de testosterona e função endotelial, é possível sugerir que testosterona compromete a função vasodilatadora das células endoteliais, pela redução da produção de fatores relaxantes e aumento de fatores contrateis derivados do endotélio.

As alterações funcionais acima descritas nos motivaram a entender quais seriam os efeitos crônicos de altas concentrações de testosterona sob a função vascular. Sendo assim, camundongos foram tratados com propionato de testosterona por 30 dias. Nos baseamos no estudo de Pirompol e colaboradores para a escolha da dose administrada. Estes autores 
observaram que ratos machos Sprague-Dawley, quando tratados com testosterona na dose de $10 \mathrm{mg} / \mathrm{kg}$ durante quatro semanas, apresentaram aumento significativo, de aproximadamente três vezes, dos níveis séricos deste hormônio quando comparados aos níveis fisiológicos em ratos tratados com veículo (Pirompol et al., 2016). Nossos achados revelam efeitos similares, onde o tratamento com propionato de testosterona aumentou os níveis séricos de testosterona total em aproximadamente três vezes, quando comparado àqueles em camundongos tratados com veículo.

Ao avaliarmos a função vascular de camundongos tratados com propionato de testosterona, observamos novamente aumento da contração induzida por fenilefrina e diminuição da vasodilatação induzida por acetilcolina.

As alterações cardiovasculares decorrentes de níveis suprafisiológicos de testosterona estão correlacionadas à desequilíbrio na produção/liberação de agentes vasodilatadores que promovem inotropismo e cronotropismo negativos, em detrimento da produção/liberação de agentes vasoconstritores que promovem inotropismo e cronotropismo positivos. Ratos Sprague-Dawley tratados com testosterona apresentaram hipertrofia cardíaca associada ao acúmulo de colágeno e inotropismo positivo associado a aumento na expressão da isoforma alfa da cadeia leve da miosina (Pirompol et al., 2016). Além disso, dados do nosso grupo demonstram que o tratamento de camundongos C57BL/6J saudáveis com testosterona compromete a função endotelial, reduzindo a biodisponibilidade de óxido nítrico, seguido por estresse oxidativo (Costa et al., 2017). Na prática clínica, indivíduos saudáveis tratados com dose única de testosterona $(500 \mathrm{mg})$ apesentam redução da excreção urinária de metabólitos do óxido nítrico, indicando menor formação deste neurotransmissor e agente vasodilatador, seguido por redução da capacidade antioxidante, também avaliada na urina destes indivíduos (Skogastierna et al., 2014). 
A testosterona livre se liga a dois tipos de receptores para andrógenos: o citoplasmático, que promove resposta celular a longo prazo e que depende de modulação gênica e proteica, promovendo efeitos denominados genômicos (Gao et al., 2005) e, ainda, a receptores localizados na membrana plasmática, que promovem resposta celular rápida, dependente do influxo de $\mathrm{Ca}^{2+}$ e da formação de segundos mensageiros, efeitos denominados não-genômicos (Steinsapir et al., 1991). Investigamos a real participação dos receptores para andrógenos nos efeitos deletérios da testosterona sob a função vascular. De tal forma, anéis de aorta torácica foram incubados com testosterona na presença de flutamida, antagonista de receptores para andrógeno (Mendoza et al., 2017). A hipercontratilidade do músculo liso vascular e a disfunção endotelial, antes observadas em resposta à incubação com testosterona, foram prevenidas na presença de flutamida. De fato, os efeitos da flutamida têm se mostrado benéficos na disfunção vascular. Em artérias de grande e pequeno calibres de ratos SpragueDawley, a flutamida promove relaxamento do músculo liso, independentemente das células endoteliais. Este efeito só é observado em machos que sofreram choque hemorrágico, condição onde os níveis de testosterona encontram-se transitoriamente aumentados (Ba et al., 2001; Ba et al., 2002).

Uma limitação deste estudo foi não ter delimitado quais receptores, citoplasmático ou ligado à membrana, estão envolvidos nos efeitos da testosterona. Entendemos que estudos adicionais devem ser realizados para esclarecer este ponto, utilizando um inibidor de transcrição gênica (actinomicina D) e da síntese proteica (cicloheximida), além do uso de testosterona conjugada a albumina, visto que o alto peso molecular da albumina impede sua passagem pela membrana plasmática, impossibilitando sua ligação com o receptor intracelular.

Recentemente têm sido descritas ações da testosterona sobre a proliferação celular e estresse oxidativo, eventos importantes que podem contribuir para as alterações funcionais e 
estruturais presentes nos vasos sanguíneos de indivíduos que fazem uso abusivo/indiscriminado de testosterona. Sendo assim, na tentativa de elucidarmos os mecanismos que estão envolvidos na disfunção vascular associada à níveis suprafisiológicos de testosterona, avaliamos a capacidade pró-oxidante deste hormônio em anéis de aorta torácica de camundongos. Usando a técnica da lucigenina, observamos que testosterona aumentou a geração de EROs. É digno de nota o uso do substrato NADH para o ensaio da lucigenina, uma vez que este substrato é crucial para a produção de EROs pela cadeia respiratória mitocondrial. Estudos do nosso grupo demonstraram que a testosterona induz geração EROs, de forma concentração e tempo dependentes, em células de músculo liso vascular, e que na presença da droga CCCP, um desacoplador mitocondrial, este aumento é prevenido (Lopes et al., 2014). Dada esta evidência, também investigamos a geração de EROs mitocondriais utilizando a droga $\mathrm{CCCP}$. De fato, como dito anteriormente, testosterona aumentou a geração de EROs em anéis de aorta torácica de camundongos. Todavia, a incubação prévia com CCCP preveniu tal geração, reforçando que o estresse oxidativo vascular induzido pela testosterona é decorrente da disfunção mitocondrial.

Investigamos a participação das EROs mitocondriais nos efeitos vasculares de altas concentrações de testosterona. Observamos que incubações prévias com CCCP preveniram os efeitos deletérios da testosterona sobre a função vascular. De maneira similar, nosso grupo demonstrou que EROs mitocondriais provenientes do tecido adiposo perivascular (PVAT) de camundongos obesos é agente causador de disfunção vascular e que o tratamento in vitro do PVAT com CCCP preveniu tal disfunção (Costa et al., 2017). Baseando-se em evidências que testosterona, ao se ligar em receptores para andrógenos, promove influxo de $\mathrm{Ca}^{2+}$ (Steinsapir et al., 1991) e que o acúmulo de $\mathrm{Ca}^{2+}$ intracelular é crucial para a geração de EROs mitocondriais (Bertero e Maack, 2018), sugerimos a via testosterona-Ca ${ }^{2+}$-EROs 
mitocondriais como intimamente envolvida na disfunção vascular induzida por níveis suprafisiológicos de testosterona.

O aumento da geração de EROs mitocondriais é um fator primordial para a ativação do inflamassoma NLRP3 (Zhou et al., 2011). No sistema cardiovascular, o inflamassoma NLRP3 possui grande importância, uma vez que células vasculares são capazes de detectar e responder a DAMPs ou PAMPs via TLRs e NLRs, levando a liberação de citocinas, quimiocinas e hormônios (Schultz et al., 2007; Foldes et al., 2010). Neste contexto, avaliamos a participação do inflamassoma NLRP3 na disfunção vascular associada à níveis suprafisiológicos de testosterona. Anéis de aorta torácica foram previamente incubados com MCC950, inibidor seletivo de NLRP3 (Coll et al., 2015). A hipercontratilidade do músculo liso vascular e a disfunção endotelial, antes observadas em resposta à incubação com testosterona, foram parcialmente prevenidas na presença de MCC950. Dados do nosso grupo demonstram que artérias mesentéricas de resistência de animais diabéticos, um modelo clássico de hiperaldosteronismo, quando incubadas com MCC950, tem sua integridade funcional restaurada (Ferreira et al., 2018. Dados ainda não publicados). Consideramos que no contexto de níveis suprafisiológicos de testosterona, novos experimentos devem ser realizados a fim de estabelecer a real associação entre a geração de EROs mitocondriais e ativação do inflamassoma NLRP3.

Camundongos knockouts para NLRP3 foram utilizados neste estudo. Similar às condições acima descritas, anéis de aorta torácica destes camundongos foram incubados com testosterona e, além disso, camundongos foram tratados cronicamente com propionato de testosterona. Nestas duas condições, os efeitos deletérios da testosterona sobre a função vascular foram prevenidos, mostrando a real participação do inflamassoma NLRP3 na disfunção vascular associada à níveis suprafisiológicos de testosterona. Estudos têm demonstrado que a ausência do inflamassoma NLRP3 previne a disfunção vascular e o 
aumento da pressão arterial em modelos experimentais de hipertensão arterial, diabetes e obesidade (Vandanmagsar et al., 2011; Shirasuna, K. et al., 2015). Nosso estudo é inédito ao demonstrar a associação entre testosterona, inflamassoma NLRP3 e função vascular.

A ativação de caspase-1 é responsável por clivar as formas imaturas de IL-1 $\beta$ e IL-18 em respostas à DAMPs e PAMPs (Franchi et al., 2009; Martinon et al., 2009). Observamos neste estudo que a incubação com testosterona e tratamento crônico com propionato de testosterona aumentaram a expressão de caspase-1 na aorta torácica. Além disso, observamos aumento dos níveis séricos de IL-1 $\beta$ nos camundongos tratados. O aumento da expressão de IL-1 $\beta$, produto final da ativação do inflamassoma NLRP3, tem sido relacionado à prejuízos da função vascular. Aortas de ratos espontaneamente hipertensos propensos ao acidente vascular encefálico (stroke-prone spontaneously hypertensive rats, SHRSP) incubadas com IL-1 $\beta$, apresentam aumento da contratilidade vascular, por mecanismos que envolvem ativação de vias de sinalização da COX e Src-quinase (Dorrance, 2007). Bruder e colaboradores demonstraram que artérias mesentéricas de resistência de camundongos C57BL/6J incubadas com IL-1 $\beta$ apresentam aumento da contração vascular e redução do relaxamento dependente das células endoteliais (Bruder et al., 2016). Além disso, a IL-1 $\beta$ induz nos vasos sanguíneos efeitos como disfunção endotelial em artérias de resistência de ratos, aumento da vasoconstrição em aortas de ratos hipertensos, contribuindo para a elevação da resistência vascular periférica; aumento na migração e proliferação de CMLV, de ratos e humanos, estimuladas com angiotensina II (ANGII) e IL-1 $\beta$, com consequente remodelamento vascular (Jiménez-Altayó et al, 2006; Aguado et al, 2015). Entendemos que expressão de IL-1 $\beta$, seja em aortas torácicas incubadas com testosterona ou em aortas provenientes de camundongos tratados com propionato de testosterona, é crucial para a disfunção vascular decorrente da ativação do inflamassoma NLRP3. 
Como dito anteriormente, a ativação do inflamassoma NLRP3 depende de duas etapas/sinais distintos. Visto que testosterona induz liberação de diversas formas de DAMPs, os quais são primordiais para ativação do primeiro sinal via ativação do NF- $\kappa \mathrm{B}$, estamos cientes da necessidade de avaliar a expressão e atividade de $\mathrm{NF}-\kappa \mathrm{B}$, a fim de elucidar como a testosterona está ativando o inflamassoma NLRP3.

Nossa hipótese inicial postula que testosterona estimula a geração de EROs mitocondriais, segundo sinal necessário para ativação do inflamassoma NLRP3. A função vascular avaliada na presença de CCCP confirma a participação das EROs mitocondriais nos efeitos da testosterona. Experimentos de biologia molecular que envolvam a avaliação da via do inflamassoma NLRP3 (caspase, IL-1 $\beta$ ) na presença de CCCP irão confirmar a associação entre EROs mitocondriais e ativação desta via.

Em resumo, os resultados por nós obtidos confirmam/sugerem que níveis suprafisiológicos de testosterona agem sobre receptores para andrógenos, o que possivelmente leva ao aumento intracelular de $\mathrm{Ca}^{2+}$, causando alterações mitocondriais e geração de EROs por esta organela. A geração de EROs mitocondriais é estimulo crucial para ativação do inflamassoma NLRP3, uma plataforma inflamatória produtora de IL-1 $\beta$ e IL-18. O acúmulo destas citocinas inflamatórias classicamente promove disfunção vascular. Sendo assim, este estudo contribui para o entendimento dos mecanismos que controlam a função vascular na condição de níveis suprafisiológicos de testosterona e sustentam a possibilidade de novas terapias para indivíduos com prejuízos vasculares por uso abusivo/indiscriminado deste hormônio. 
7. Conclusão 
Juntos, nossos resultados fornecem evidências que níveis suprafisiológicos de testosterona contribuem para a geração de EROs mitocondriais por células vasculares, evento que estaria associado a aumento da atividade do inflamassoma NLRP3, conduzindo a disfunção vascular. Sendo assim, este estudo contribui para o entendimento dos mecanismos envolvidos na disfunção vascular induzida por níveis suprafisiológicos de testosterona. 
8. Referências Bibliográficas 
AGUADO, A. et al. HuR mediates the synergistic effects of angiotensin II and IL-1 $\beta$ on vascular COX-2 expression and cell migration. British journal of pharmacology, v. 172, n. 12, p. 3028-3042, 2015.

AKISHITA, M. et al. Low testosterone level is an independent determinant of endothelial dysfunction in men. Hypertension Research, v. 30, n. 11, p. 1029-1034, Jun, 2007.

BASSIL, N. et al. The benefits and risks of testosterone replacement therapy: a review. Therapeutics and clinical risk management, v. 5, p. 427, 2009.

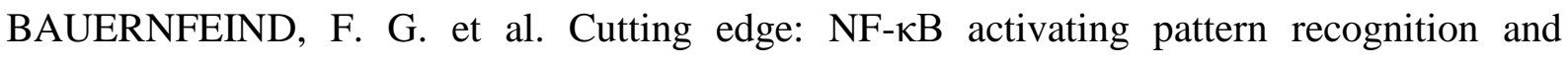
cytokine receptors license NLRP3 inflammasome activation by regulating NLRP3 expression. The Journal of Immunology, v. 183, n. 2, p. 787-791, May, 2009.

$\mathrm{BEBO}, \mathrm{B} . \mathrm{F}$. et al. Androgens alter the cytokine profile and reduce encephalitogenicity of myelin-reactive T cells. The Journal of Immunology, v. 162, n. 1, p. 35-40, 1999.

BELLIDO, T. et al. Regulation of interleukin-6, osteoclastogenesis, and bone mass by androgens. The role of the androgen receptor. Journal of Clinical Investigation, v. 95, n. 6, p. 2886, 1995.

BEN-NATHAN, D. et al. Androstenediol and dehydroepiandrosterone protect mice against lethal bacterial infections and lipopolysaccharide toxicity. Journal of Medical Microbiology, v. 48, n. 5, p. 425-431, 1999.

BERTERO, E.; MAACK, C. Calcium signaling and reactive oxygen species in mitochondria. Circulation Research, v. 122, n. 10, p. 1460-1478, 2018.

BHASIN, S. et al. Testosterone therapy in men with androgen deficiency syndromes: an Endocrine Society clinical practice guideline. The Journal of Clinical Endocrinology \& Metabolism, v. 95, n. 6, p. 2536-2559, 2010.

BRADFORD, M. M. A rapid and sensitive method for the quantitation of microgram quantities of protein utilizing the principle of protein-dye binding. Analytical Biochemistry, v. 72, p. 248-54, May 71976. 
BRUDER-NASCIMENTO, T. et al. nlrP3 inflammasome Mediates aldosterone-induced Vascular Damage. Circulation, v. 134, n. 23, p. 1880-1866, December, 2016.

CASSEL, S. L. et al. The Nalp3 inflammasome is essential for the development of silicosis. Proceedings of the National Academy of Sciences, v. 105, n. 26, p. 9035-9040, 2008.

CHAN, Y. X. et al. Testosterone, dihydrotestosterone and estradiol are differentially associated with carotid intima-media thickness and the presence of carotid plaque in men with and without coronary artery disease. Endocrine Journal, v. 62, n. 9, p. 777-786, 2015.

CHEN, Y. et al. Androgen-dependent angiotensinogen and renin messenger RNA expression in hypertensive rats. Hypertension, v. 19, n. 5, p. 456-463, 1992.

CHEN, Y. et al. Endothelial Nlrp3 inflammasome activation associated with lysosomal destabilization during coronary arteritis. Biochimica et Biophysica Acta (BBA)-Molecular Cell Research, v. 1853, n. 2, p. 396-408, 2015.

CHIGNALIA, A. Z. et al. Testosterone induces leucocyte migration by NADPH oxidasedriven ROS-and COX2-dependent mechanisms. Clinical Science, v. 129, n. 1, p. 39-48, 2015.

CHIGNALIA, A. Z. et al. Testosterone induces vascular smooth muscle cell migration by NADPH oxidase and c-Src-dependent pathways. Hypertension, v. 59, n. 6, p. 1263-1271, 2012.

COLL, R. C. et al. A small-molecule inhibitor of the NLRP3 inflammasome for the treatment of inflammatory diseases. Nature Medicine, v. 21, n. 3, p. 248-55, Mar 2015.

D'AGOSTINO, P. et al. Sex hormones modulate inflammatory mediators produced by macrophages. Annals of the New York Academy of Sciences, v. 876, n. 1, p. 426-429, 1999. 
DALAL, M.; et al. Testosterone therapy ameliorates experimental autoimmune encephalomyelitis and induces a $\mathrm{T}$ helper 2 bias in the autoantigen-specific $\mathrm{T}$ lymphocyte response. The Journal of Immunology, v. 159, n. 1, p. 3-6, 1997.

DAVIS, B. K.; WEN, H.; TING, J. P.-Y. The inflammasome NLRs in immunity, inflammation, and associated diseases. Annual Review of Immunology, v. 29, p. 707-735, Jan, 2011.

DEATH, Alison K. et al. Dihydrotestosterone promotes vascular cell adhesion molecule-1 expression in male human endothelial cells via a nuclear factor- $\kappa \mathrm{B}$-dependent pathway. Endocrinology, v. 145, n. 4, p. 1889-1897, 2004.

DOI, T. et al. Mizoribine ameliorates renal injury and hypertension along with the attenuation of renal caspase-1 expression in aldosterone-salt-treated rats. PLoS One, v. 9, n. 4, p. e93513, 2014.

DORRANCE, A. M. Interleukin 1-beta (IL-1beta) enhances contractile responses in endothelium-denuded aorta from hypertensive, but not normotensive, rats. Vascular Pharmacology, v. 47, n. 2-3, p. 160-5, Aug-Sep 2007.

EBRAHIMI, F.; CHRIST-CRAIN, M. Metabolic syndrome and hypogonadism-two peas in a pod. Swiss Med Wkly, v. 146, p. w142832016, Mar, 2016.

ELLISON, K. E. et al. Androgen regulation of rat renal angiotensinogen messenger RNA expression. The Journal of Clinical Investigation, v. 83, n. 6, p. 1941-1945, 1989.

ESPINOSA, V.; RIVERA, A. Cytokines and the regulation of fungus-specific CD4 T cell differentiation. Cytokine, v. 58, n. 1, p. 100-106, 2012.

ESTRADA, M. et al. Testosterone stimulates intracellular calcium release and mitogenactivated protein kinases via a $G$ protein-coupled receptor in skeletal muscle cells. Endocrinology, v. 144, n. 8, p. 3586-3597, 2003. 
FÖLDES, G et al. Innate immunity in human embryonic stem cells: comparison with adult human endothelial cells. PLoS One, v. 5, n. 5, p. 10501, 2010.

FRANCHI, L et al. The inflammasome: a caspase-1-activation platform that regulates immune responses and disease pathogenesis. Nature Immunology, v. 10, n. 3, p. 241, 2009. FUJISUE, K. et al. Colchicine Improves Survival, Left Ventricular Remodeling, and Chronic Cardiac Function After Acute Myocardial Infarction. Circulation Journal, v. 81, p.11741182, Mar, 2017.

FULLERTON, J. N.; GILROY, D. W. Resolution of inflammation: a new therapeutic frontier. Nature Reviews Drug Discovery, v. 15, n. 8, p. 551-567, 2016.

GAZIANO, T. A. et al. Growing epidemic of coronary heart disease in low-and middleincome countries. Current Problems in Cardiology, v. 35, n. 2, p. 72-115, 2010.

GERSH, B. J. et al. Novel therapeutic concepts the epidemic of cardiovascular disease in the developing world: global implications. European Heart Journal, v. 31, n. 6, p. 642-648, 2010.

GORNSTEIN, R. A. et al. Androgens modulate interleukin-6 production by gingival fibroblasts in vitro. Journal of Periodontology, v. 70, n. 6, p. 604-609, 1999.

GROBAN, L. et al. Sex and Gender Differences in Cardiovascular Disease. In: Sex Differences in Physiology. p. 61-87, 2016.

GUO, H. et al. NLRP3 Deficiency Attenuates Renal Fibrosis and Ameliorates Mitochondrial Dysfunction in a Mouse Unilateral Ureteral Obstruction Model of Chronic Kidney Disease. Mediators of Inflammation, v. 2017, Feb, 2017.

HANSEN, S. S. et al. The role of NADPH oxidases in diabetic cardiomyopathy. Biochimica et Biophysica Acta (BBA)-Molecular Basis of Disease, 2017.

HARTGENS, F.; KUIPERS, H. Effects of androgenic-anabolic steroids in athletes. Sports Medicine, v. 34, n. 8, p. 513-554, 2004. 
HATAKEYAMA, $H$. et al. Testosterone inhibits tumor necrosis factor- $\alpha$-induced vascular cell adhesion molecule-1 expression in human aortic endothelial cells. FEBS Letters, v. 530, n. 1-3, p. 129-132, 2002.

HAWK, T. et al. Testosterone increases and estradiol decreases middle cerebral artery occlusion lesion size in male rats. Brain Research, v. 796, n. 1, p. 296-298, 1998.

HOFBAUER, L. C.; TEN, R. M.; KHOSLA, S. The anti-androgen hydroxyflutamide and androgens inhibit interleukin- 6 production by an androgen-responsive human osteoblastic cell line. Journal of Bone and Mineral Research, v. 14, n. 8, p. 1330-1337, 1999.

JIMÉNEZ-ALTAYÓ, F. et al. Increased superoxide anion production by interleukin-1 $\beta$ impairs nitric oxide-mediated relaxation in resistance arteries. Journal of Pharmacology and Experimental Therapeutics, v. 316, n. 1, p. 42-52, 2006.

JIN, C.; FLAVELL, R. A. Molecular mechanism of NLRP3 inflammasome activation. Journal of Clinical Immunology, v. 30, n. 5, p. 628-631, Jun, 2010.

JIN, H. et al. Testosterone alleviates tumor necrosis factor-alpha-mediated tissue factor pathway inhibitor downregulation via suppression of nuclear factor-kappa B in endothelial cells. Asian Journal of Andrology, v. 11, n. 2, p. 266, 2009.

KAHLENBERG, J.; DUBYAK, G. R. Mechanisms of caspase-1 activation by P2X 7 receptor-mediated K+ release. American Journal of Physiology-Cell Physiology, v. 286, n. 5, p. C1100-C1108, 2004.

KALRA, S. et al. Testosterone replacement in male hypogonadism. Clinical Pharmacology: Advances and Applications, v. 2, p. 149, 2010.

KIMURA, M. et al. Dehydroepiandrosterone decreases serum tumor necrosis factor- $\alpha$ and restores insulin sensitivity: independent effect from secondary weight reduction in genetically obese Zucker fatty rats. Endocrinology, v. 139, n. 7, p. 3249-3253, 1998.

KLONER, R. A. et al. Testosterone and cardiovascular disease. Journal of the American College of Cardiology, v. 67, n. 5, p. 545-557, Feb, 2016. 
KOKA, S. et al. Endothelial NLRP3 Inflammasome Activation and Arterial Neointima Formation Associated with Acid Sphingomyelinase during Hypercholesterolemia. Redox Biology, v. 13, p. 336-344, Jun, 2017.

KOMUKAI, K. et al. Gender and the renin-angiotensin-aldosterone system. Fundamental \& Clinical Pharmacology, v. 24, n. 6, p. 687-698, 2010.

KRISHNAN, S. M. et al. Inflammasome activity is essential for one kidney/deoxycorticosterone acetate/salt-induced hypertension in mice. British Journal of Pharmacology, v. 173, n. 4, p. 752-765, 2016.

LAUGHLIN, G. A.; BARRETT-CONNOR, E.; BERGSTROM, J. Low serum testosterone and mortality in older men. The Journal of Clinical Endocrinology \& Metabolism, v. 93, n. 1, p. 68-75, Jan, 2008.

LI, R. et al. Testosterone improves erectile function through inhibition of reactive oxygen species generation in castrated rats. PeerJ, v. 4, May, 2016.

LI, Z. G.; DANIS, V. A.; BROOKS, P. M. Effect of gonadal steroids on the production of IL1 and IL-6 by blood mononuclear cells in vitro. Clinical and Experimental Rheumatology, v. 11, n. 2, p. 157-162, 1993.

LIDDIARD, K. et al. Macrophage heterogeneity and acute inflammation. European Journal of Immunology, v. 41, n. 9, p. 2503-2508, 2011.

LING, Y. H. et al. Anakinra reduces blood pressure and renal fibrosis in one kidney/DOCA/salt-induced hypertension. Pharmacological Research, v. 116, p. 77-86, 2017.

LIU, P. et al. Activation of the NLRP3 inflammasome induces vascular dysfunction in obese OLETF rats. Biochemical and Biophysical Research Communications, v. 468, n. 1-2, p. 319-25, Dec 4-11 2015. 
LIVA, S. M.; VOSKUHL, R. R. Testosterone acts directly on CD4+ T lymphocytes to increase IL-10 production. The Journal of Immunology, v. 167, n. 4, p. 2060-2067, 2001.

LOBATO, N. S. et al. The adipokine chemerin augments vascular reactivity to contractile stimuli via activation of the MEK-ERK1/2 pathway. Life sciences, v. 91, n. 13, p. 600-606, 2012.

LOPES, R. A. M. et al. Testosterone and vascular function in aging. Frontiers in Physiology, v. 3, Apr, 2012.

LOPES, R. A. M. et al. Testosterone induces apoptosis in vascular smooth muscle cells via extrinsic apoptotic pathway with mitochondria-generated reactive oxygen species involvement. American Journal of Physiology-Heart and Circulatory Physiology, v. 306, n. 11, p. H1485-H1494, 2014.

MAGGIO, M. et al. Circulating inflammatory cytokine expression in men with prostate cancer undergoing androgen deprivation therapy. Journal of Andrology, v. 27, n. 6, p. 725 $728,2006$.

MAGGIO, M. et al. The relationship between testosterone and molecular markers of inflammation in older men. Journal of Endocrinological Investigation, v. 28, n. 11, p. 116$119,2005$.

MALKIN, C. J. et al. The effect of testosterone replacement on endogenous inflammatory cytokines and lipid profiles in hypogonadal men. The Journal of Clinical Endocrinology \& Metabolism, v. 89, n. 7, p. 3313-3318, 2004.

MARTINON, F-; MAYOR, A-; TSCHOPP, J- The inflammasomes: guardians of the body. Annual Review of Immunology, v. 27, p. 229-265, 2009.

MCCROHON, J. A. et al. Androgen exposure increases human monocyte adhesion to vascular endothelium and endothelial cell expression of vascular cell adhesion molecule1. Circulation, v. 99, n. 17, p. 2317-2322, 1999. 
MUKHERJEE, T. K. et al. Testosterone attenuates expression of vascular cell adhesion molecule-1 by conversion to estradiol by aromatase in endothelial cells: implications in atherosclerosis. Proceedings of the National Academy of Sciences, v. 99, n. 6, p. 40554060, 2002.

MULLIGAN, T. et al. Prevalence of hypogonadism in males aged at least 45 years: the HIM study. International Journal of Clinical Practice, v. 60, n. 7, p. 762-769, Jul, 2006.

NORDSTRÖM, A. et al. Higher muscle mass but lower gynoid fat mass in athletes using anabolic androgenic steroids. The Journal of Strength \& Conditioning Research, v. 26, n. 1, p. 246-250, 2012.

NOVAK, K. Cardiovascular disease increasing in developing countries, v. 4, p. 989-990, 1998.

OGURA, Y.; SUTTERWALA, F. S.; FLAVELL, R. A. The inflammasome: first line of the immune response to cell stress. Cell, v. 126, n. 4, p. 659-662, Aug, 2006.

PATEL, M. N. et al. Inflammasome Priming in Sterile Inflammatory Disease. Trends in Molecular Medicine,v.22, n. 2, p. 165-180, Feb, 2017.

PEARSON, L. J. et al. Regulation of endothelin-1 release from human endothelial cells by sex steroids and angiotensin-II. Peptides, v. 29, n. 6, p. 1057-1061, 2008.

PERRY, P. J. et al. Anabolic steroid use in weightlifters and bodybuilders: an internet survey of drug utilization. Clinical Journal of Sport Medicine, v. 15, n. 5, p. 326-330, 2005.

POSMA, E. et al. The Effect of Testosterone on Cytokine Production in the Specific and Nonspecific Immune Response. American Journal of Reproductive Immunology, v. 52, n. 4, p. 237-243, 2004. 
POULSEN, C. B. et al. Differences in hypercholesterolemia and atherogenesis induced by common androgen deprivation therapies in male mice. Journal of the American Heart Association, v. 5, n. 2, p. e002800, 2016.

RAZMARA, A.; KRAUSE, D. N.; DUCKLES, S. P. Testosterone augments endotoxinmediated cerebrovascular inflammation in male rats. American Journal of PhysiologyHeart and Circulatory Physiology, v. 289, n. 5, p. H1843-H1850, 2005.

ROVIRA-LLOPIS, S. et al. Low testosterone levels are related to oxidative stress, mitochondrial dysfunction and altered subclinical atherosclerotic markers in type 2 diabetic male patients. Free Radical Biology and Medicine, v. 108, p. 155-162, Mar, 2017.

SÁ, E. Q. C. D. et al. Serum testosterone and cardiovascular disease in men. Arquivos Brasileiros de Endocrinologia \& Metabologia, 53, 915-922, 2009.

SCHRODER, K.; TSCHOPP, J. The inflammasomes. Cell, v. 140, n. 6, p. 821-832, Mar, 2010.

SCHULTZ, K et al. Endogenous interleukin-1 $\alpha$ promotes a proliferative and proinflammatory phenotype in human vascular smooth muscle cells. American Journal of Physiology-Heart and Circulatory Physiology, v. 292, n. 6, p. H2927-H2934, 2007.

SHIRASUNA, K. et al. NLRP3 deficiency improves angiotensin II-induced hypertension but not fetal growth restriction during pregnancy. Endocrinology, v. 156, n. 11, p. 4281-4292, Sep, 2015.

SHORES, M. M. et al. Low serum testosterone and mortality in male veterans. Archives of Internal Medicine, v. 166, n. 15, p. 1660-1665, Aug, 2006.

SKOGASTIERNA, C. et al. A supraphysiological dose of testosterone induces nitric oxide production and oxidative stress. European Journal of Preventive Cardiology, v. 21, n. 8, p. 1049-1054, 2014. 
SU, C. L. et al. The effects of testosterone on the expression of inflammatory factors in 3T3L1 adipocytes and its mechanism. Zhonghua yi xue za zhi, v. 89, n. 21, p. 1493-1497, 2009. SUZUKI, H. et al. In vivo evidence for microvascular oxidative stress in Spontaneously Hypertensive Rats. Hypertension, v. 25, n. 1, p. 1083-1089, Apr, 1995.

TASGIN, E. et al. Effects of single dose administered nandrolone decanoate on serum cytokine levels and some biochemical parameters in male and female rats. Biomedical Research, v. 28, n. 8, p. 3727-3730, 2017.

TOSTES, R. C. et al. Reactive oxygen species: players in the cardiovascular effects of testosterone. American Journal of Physiology-Regulatory, Integrative and Comparative Physiology, v. 310, n. 1, p. R1-R14, 2016.

TOUSOULIS, D et al. Role of inflammation and oxidative stress in endothelial progenitor cell function and mobilization: therapeutic implications for cardiovascular diseases. Atherosclerosis, v. 201, n. 2, p. 236-247, 2008.

VANDANMAGSAR, B. et al. The NLRP3 inflammasome instigates obesity-induced inflammation and insulin resistance. Nature Medicine, v. 17, n. 2, p. 179, 2011.

VICENCIO, J. M. et al. Testosterone induces an intracellular calcium increase by a nongenomic mechanism in cultured rat cardiac myocytes. Endocrinology, v. 147, n. 3, p. 1386-1395, 2006.

VIOLA, H. M.; HOOL, L. C. How does calcium regulate mitochondrial energetics in the heart?-new insights. Heart, Lung and Circulation, v. 23, n. 7, p. 602-609, 2014.

YOUNG, T. A. et al. Reactive oxygen species production by the mitochondrial respiratory chain in isolated rat hepatocytes and liver mitochondria: studies using myxothiazol. Archives of Biochemistry and Biophysics, v. 405, n. 1, p. 65-72, Sep 12002. 
ZHANG, R. et al. Involvement of calcium, reactive oxygen species, and ATP in hexavalent chromium-induced damage in red blood cells. Cellular Physiology and Biochemistry, v. 34, n. 5 , p. $1780-1791,2014$.

ZHOU, R et al. A role for mitochondria in NLRP3 inflammasome activation. Nature, v. 469, n. 7329, p. 221, 2011. 
Anexos 


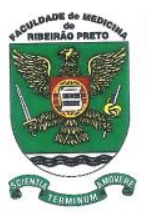

\section{UNIVERSIDADE DE SÃO PAULO FACULDADE DE MEDICINA DE RIBEIRÃO PRETO COMISSÃO DE ÉTICA NO USO DE ANIMAIS}

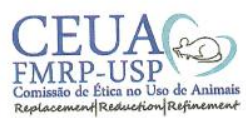

\section{$\underset{65 \text { anos } U S P}{\text { FMPP }}$}

\section{$C E R T I F I C A D O$}

Certificamos que o Protocolo intitulado "Ativação do complexo NLRP3 inflamassoma como potencial mecanismo envolvido na disfunção vascular em resposta a níveis suprafisiológicos de testosterona", registrado com o número 032/2018, sob a responsabilidade da Profa. Dra. Rita de Cassia Aleixo Tostes Passaglia, envolvendo a produção, manutenção ou utilização de animais pertencentes ao filo Chordata, subfilo Vertebrata (exceto humanos) para fins de pesquisa científica, encontra-se de acordo com os preceitos da Lei $n^{\circ} 11.794$ de 8 de outubro de 2008, do Decreto ${ }^{\circ} 6.899$ de 15 de julho de 2009 e com as normas editadas pelo Conselho Nacional de Controle de Experimentação Animal (CONCEA), e foi APROVADO pela Comissão de Ética no Uso de Animais da Faculdade de Medicina de Ribeirão Preto da Universidade de São Paulo em reunião de 07 de maio de 2018.

Este Protocolo prevê a utilização de 142 camundongos C57B1/6 machos pesando $25 \mathrm{~g}$ oriundos do Serviço de Biotério da Prefeitura do Campus de Ribeirão Preto da Universidade de São Paulo e 142 camundongos Nalp3 KO machos pesando 25g oriundos do Centro de Criação de Camundongos Especiais da Faculdade de Medicina de Ribeirão Preto da Universidade de São Paulo. Vigência da autorização: 07/05/2018 a 31/12/2019.

We certify that the Protocol $n^{\circ} 032 / 2018$, entitled "Activation of the complex NLRP3 inflammasome with potential mechanism involved in vascular dysfunction in response to suprahysiological levels of testosterone", is in accordance with the Ethical Principles in Animal Research adopted by the National Council for the Control of Animal Experimentation (CONCEA) and was approved by the Local Animal Ethical Committee from Ribeirão Preto Medical School of the University of São Paulo in 05/07/2018. This protocol involves the production, maintenance or use of animals from phylum Chordata, subphylum Vertebrata (except humans) for research purposes, and includes the use of 142 male C57B1/6 mice weighing $25 \mathrm{~g}$ from the Central Animal House of Ribeirao Preto Medical School and 142 male Nalp3 $\mathrm{KO}$ mice weighing $25 \mathrm{~g}$ from the Breeding Center of Special Mice of Ribeirao Preto Medical School, University of São Paulo. This certificate is valid until $12 / 31 / 2019$. 